\title{
Characterization of the Selective Indoleamine 2,3-Dioxygenase-1 (IDO1) Catalytic Inhibitor EOS200271/PF-06840003 Supports IDO1 as a Critical Resistance Mechanism to PD-(L)1 Blockade Therapy
}

\author{
Bruno Gomes ${ }^{1}$, Gregory Driessens ${ }^{1}$, Derek Bartlett $^{2}$, Danying Cai $^{3}$, Sandra \\ Cauwenberghs ${ }^{1}$, Stefano Crosignani ${ }^{1}$, Deepak Dalvie ${ }^{2}$, Sofie Denies ${ }^{1}$, Christopher P. \\ Dillon $^{2}$, Valeria R. Fantin', Jie Guo ${ }^{2}$, Marie-Claire Letellier ${ }^{1}$, Wenlin $\mathrm{Li}^{2}$, Karen \\ Maegley ${ }^{2}$, Reece Marillier ${ }^{1}$, Nichol Miller ${ }^{2}$, Romain Pirson ${ }^{1}$, Virginie Rabolli ${ }^{1}$, Chad \\ Ray $^{2}$, Nicole Streiner ${ }^{2}$, Vince R. Torti ${ }^{2}$, Konstantinos Tsaparikos ${ }^{2}$, Benoit van den \\ Eynde $^{1}$, Martin Wythes ${ }^{2}$, Li-Chin Yao $^{3}$, Xianxian Zheng ${ }^{2}$, Joseph Tumang ${ }^{2}$, and Manfred \\ Kraus $^{2}$ \\ ${ }^{1}$ iTeos Therapeutics SA, Rue Auguste Piccard 48, 6041 Gosselies, Belgium \\ ${ }^{2}$ Pfizer Inc., 10777 Science Center Drive, San Diego, CA 92121, USA \\ ${ }^{3}$ The Jackson Laboratory, 1650 Santa Ana Avenue, Sacramento, CA 95838, USA
}

B. Gomes and G. Driessens contributed equally to this article

Running Title: Catalytic Indoleamine 2,3-dioxygenase-1 PF-06840003

Keywords: Indoleamine 2,3-dioxygenase-1, EOS200271/PF-06840003, PD-L1, kynurenine, immunotherapy resistance

Financial support: iTeos is supported by the Walloon region of Belgium and the FEDER (European fund for economic and regional development).

Corresponding Authors: Manfred Kraus, Pfizer Inc., 10777 Science Center Drive, San Diego, CA 92121, USA; Phone: 858-622-7313; E-mail: Manfred.Kraus@Pfizer.com; Gregory Driessens, iTeos Therapeutics SA, Rue Auguste Piccard 48, 6041 Gosselies, Belgium; Phone: +32-71-960152; E-mail: gregory.driessens@iteostherapeutics.com

\section{Disclosure of Potential Conflicts of Interest}

Derek Bartlett, Deepak Dalvie, Christopher P. Dillon, Valeria Fantin, Jie Guo, Wenlin Li, Karen Maegley, Nichol Miller, Nicole Streiner, Vince R. Torti, Konstantinos Tsaparikos, Martin Wythes, Xianxian Zheng, Joseph Tumang and Manfred Kraus are current or former employees and/or have ownership interest (including patents) in Pfizer.

Bruno Gomes, Gregory Driessens, Sandra Cauwenberghs, Stefano Crosignani, Sofie Denies, Marie-Claire Letellier, Reece Marillier, Romain Pirson, Virginie Rabolli, Benoit 
van den Eynde are current or former employees and/or have ownership interest (including patents) in iTeos.

No potential conflicts of interest were disclosed by the other authors.

Word counts: $\quad$ Abstract: 200; Introduction: 379; Materials and Methods: 1252;

Results: 2424; Discussion: 1228

References: $\quad 36$

Number of figures: 4

Number of tables: 2 


\section{Abbreviations}

$\mathrm{AUC}=$ area under the curve

CLp $=$ plasma clearance

$\mathrm{CNS}=$ central nervous system

$\mathrm{CSF}=$ cerebrospinal fluid

dIDO1 = Dog IDO1 enzyme

hIDO1 = Human IDO1 enzyme

$\mathrm{IC}_{50}=$ Concentration of inhibitor that gives $50 \%$ inhibition

$\mathrm{IC}_{90}=$ Concentration of inhibitor that gives $90 \%$ inhibition

IDO1 = indoleamine 2,3-dioxygenase 1

IDO2 = indoleamine 2,3-dioxygenase 2

IFN $\gamma=$ Interferon gamma

Kdapp= Apparent dissociation constant;

Kdapp Ferrous $=$ Kdapp when test article is titrated into the ferrous form of IDO1

Kdapp Ferric $(+\mathrm{O} 2)=$ Kdapp when test article is titrated into the ferric form of IDO1 without measures to remove oxygen

Kdapp Ferric $(-\mathrm{O} 2)=$ Kdapp when test article is titrated into the ferric form of IDO1 following oxygen depletion

Kdapp Ferric (- O2, +Trp) = Kdapp when test article is titrated into the ferric form of

$\mathrm{KYN}=$ Kynurenine

IDO1 following oxygen depletion in the presence of tryptophan

LPS = lipopolysaccharide

mIDO1 $=$ Mouse IDO1 enzyme

NT $=$ Not tested

$\mathrm{O}_{2}=$ Molecular oxygen

TDO2 = tryptophan-2,3-dioxygenase

$\mathrm{TME}=$ tumor microenvironment

Trp $=$ Tryptophan

Vss = apparent volume of distribution at steady state 


\begin{abstract}
Tumors use Indoleamine 2,3-dioxygenase-1 (IDO1) as a major mechanism to induce an immunosuppressive microenvironment. IDO1 expression is upregulated in many cancers and considered to be a resistance mechanism to immune checkpoint therapies. IDO1 is induced in response to inflammatory stimuli such as IFN $\gamma$ and promotes immune tolerance by depleting tryptophan and producing tryptophan catabolites including kynurenine in the tumor microenvironment. This leads to effector T-cell anergy and enhanced $\mathrm{T}_{\text {reg }}$ function through upregulation of FoxP3. As a nexus for the induction of key immunosuppressive mechanisms, IDO1 represents an important immunotherapeutic target in oncology. Here, we report the identification and characterization of the novel selective, orally bioavailable IDO1 inhibitor EOS200271/PF-06840003. It reversed IDO1-induced T-cell anergy in vitro. In mice carrying syngeneic tumor grafts, PF06840003 reduced intratumoral kynurenine levels by over $80 \%$ and inhibited tumor growth both in monotherapy and, with an increased efficacy, in combination with antibodies blocking the immune checkpoint ligand PD-L1. We demonstrate that anti-PDL1 therapy results in increased IDO1 metabolic activity thereby providing additional mechanistic rationale for combining PD-(L)1 blockade with IDO1 inhibition in cancer immunotherapies. Supported by these preclinical data and favorable predicted human pharmacokinetic properties of PF-06840003, a Phase-1 open-label, multicenter clinical study (NCT02764151) has been initiated.
\end{abstract}




\section{Introduction}

Immunotherapy has now been clinically validated as an effective approach for cancer therapy. Clinical trials with antibodies blocking cytotoxic $\mathrm{T}$ lymphocyte-associated antigen 4 (CTLA-4) and programmed cell death protein 1 (PD-1) or programmed cell death ligand 1 (PD-L1) have led the way to a second generation of immune checkpoint inhibitors (1). Most targets in the immuno-oncology field are co-stimulatory or coinhibitory receptors modulated through monoclonal antibody agonism or blockade, respectively. In addition, small molecules targeting intracellular mediators of tumor immune escape are now also being developed as cancer immunotherapeutics. Examples supported by increasing data include IDO1, ROR $\gamma$ t or certain protein kinases (2).

IDO1 is a heme-containing dioxygenase that catalyzes the oxidation of L-tryptophan to $\mathrm{N}$-formyl kynurenine in the first and rate-limiting step of tryptophan catabolism. N'formyl kynurenine is subsequently converted by formamidase to L-kynurenine and additional downstream immunologically-active metabolites via the kynurenine pathway. IDO1 promotes peripheral anti-tumor immune tolerance (3). Its expression and activity are often elevated in the tumor microenvironment, typically in response to inflammatory stimuli such as interferon gamma (IFN $\gamma$ ) (4). The exact mechanisms by which IDO1 activity down-regulates anti-tumor immunity are still unclear. They may involve sensing of tryptophan depletion via GCN2 kinase mediated phosphorylation of eIF2a and mTOR. This initiates a stress response resulting in cell cycle arrest of T-cells $(5,6)$. In addition or alternatively, binding of L-kynurenine or its metabolites to the aryl hydrocarbon receptor (AhR) causes effector T-cell apoptosis or differentiation into immunosuppressive regulatory T-cells (7-10).

IDO1 expression is associated with a poor prognosis in several cancer indications (1114). As such, IDO1 is a target of high interest for cancer immunotherapy and IDO1inhibiting drugs have become a focus of research and development efforts for tumor immune therapy (15). Clinical trials with IDO1 pathway inhibitors are underway, including indoximod (d-1-methyl-tryptophan) and epacadostat (INCB024360). Among these, INCB024360 inhibits the catalytic activity of IDO1 (16-18). Here we describe the initial characterization of EOS200271/PF-06840003, a novel and selective, orally bioavailable IDO1 catalytic inhibitor with promising in vivo efficacy and predicted human pharmacokinetic properties. In addition, we show a mechanistic link between antiPD-L1 treatment and IDO1 activity, thereby implicating IDO1 as a critical driver of adaptive resistance to therapies targeting the PD-1/PD-L1 axis. Based on our findings, 
PF-06840003 was selected for further clinical evaluation in a Phase-1 study. 


\section{Material and Methods}

\section{Expression, Purification and Enzymatic Activity}

Full length cDNAs for human IDO1, indoleamine 2,3-dioxygenase 2 (IDO2) and tryptophan 2,3-dioxygenase (TDO2) were cloned into pFastbac-1 and for mouse and dog IDO1 into pET24a vectors. The inhibition of IDO1, IDO2 and TDO2 was measured by quantitating tryptophan and kynurenine by MS (details in Supplementary Methods).

\section{Protein Binding}

PF-06840003 (same as EOS200271), PF-06840002 and PF-06840001 were synthesized as described (19). The protein binding of PF-06840002 and PF-06840001 was determined by equilibrium dialysis in pooled male and female mouse plasma by incubating PF06840003 at $2 \mu \mathrm{M}$.

\section{Cell Lines and Culture Conditions}

HeLa (CCL-2, 2014), THP-1 (TIB-202, 2013), A172 (CRL-1620, 2014), SKOV3 (HTB77, 2015), MDA-MB-231 (HTB-26, 2014) human cell lines and B16-F10 (CRL-6475, 2010), CT26 (CRL-2638, 2014), EMT6 (CRL-2755, 2016), Renca (CRL-2947, 2013), 4T1 (CRL-2539, 2016) mouse cell lines were purchased from ATCC (ATCC-No, year obtained) and cultured according to their recommended conditions. The MC38 cell line was provided by Dr. Antoni Ribas (UCLA) in 2011. The murine PanO2 cell line was obtained from the National Cancer Institute (Bethesda, MD). MC38 and PanO2 cells were cultured in RPMI with 10\% FBS. P815 mTDO2 cl12 cells were generated and cultured as described (20). Cell lines routinely tested negative for Mycoplasma spp. contamination (MycoAlert, Lonza). ATCC verifies cell line identity with short tandem repeat (STR) analysis. Pfizer authenticated cell lines in their central cell bank by STR and interspecies contamination analysis that was performed at IDEXX BioResearch with the CellCheck 16 Plus - human and CellCheck Plus - mouse assays.

\section{IDO1 Catalytic Activity Cellular Assays}


20,000 HeLa cells were seeded per well in $200 \mu \mathrm{L}$ growth media in a 96-well plate and allowed to adhere overnight. Then, growth media was replaced with $200 \mu \mathrm{L}$ reduced (2\%) serum media containing $100 \mathrm{ng} / \mathrm{mL}$ IFN $\gamma(\mathrm{R} \& \mathrm{D}, 285-\mathrm{IF}-100)$ and incubated for $48 \mathrm{~h}$ to induce IDO expression. 100,000 THP-1 cells were seeded in $100 \mu \mathrm{L}$ IMDM with 4\% FBS, $100 \mathrm{ng} / \mathrm{mL}$ LPS (Sigma, L-4391), and $50 \mathrm{ng} / \mathrm{mL}$ IFN $\gamma$ to induce IDO expression. In both assays eleven 3-fold dilutions of compounds PF-06840003, PF-06840002 or PF06840001 beginning at $50 \mu \mathrm{M}$ were added for $24 \mathrm{~h} .100 \mu \mathrm{L}$ supernatant was transferred to a v-bottom 96 well plate. $30 \mu \mathrm{L} 30 \%$ trichloroacetic acid (TCA) was added and centrifuged at 3,000 RPM for 10 min. $100 \mu \mathrm{L}$ was transferred to a flat-bottom 96-well plate and combined with $100 \mu \mathrm{L}$ of $2 \%$ 4-(dimethylamino)benzaldehyde in acetic acid to derivatize $\mathrm{N}$-formyl kynurenine to kynurenine for quantitative colorimetric readout. Assay plates were read at $\mathrm{A}_{492}$ on an Envision plate reader (Perkin Elmer). $\mathrm{IC}_{50}$ values were calculated using Activity Base software (Version 8.0.5.4) and non-linear regression of percent inhibition versus $\log _{10}$ concentration of IDO inhibitor compound.

\section{TDO2 Catalytic Activity Cellular Assays}

A172 cells were incubated at 12,500 cells/well with increasing concentrations of compounds for 16-18h. THP-1 cells $(100,000$ cells/well) were stimulated with $2 \mathrm{ng} / \mathrm{ml}$ phorbol-myristate acetate (PMA) for $24 \mathrm{~h}$ and then incubated for $24 \mathrm{~h}$ with compounds. P815 mTDO2 cl12 cells (50,000 cells/well) were incubated for 16-18h with compounds. Kynurenine concentrations were determined as described above.

\section{Co-Culture Assay}

SKOV3 cells were seeded in IMDM with $10 \%, 25 \%$ or $50 \%$ of human serum (Sigma) with increasing concentrations of PF-06840003 and then irradiated (10,000 rad). Human peripheral blood mononuclear cells were isolated from buffy coats, purified by density gradient centrifugation using Lymphoprep $^{\mathrm{TM}}$ (StemCell), stimulated with CD3/CD28 beads (Invitrogen) and hIL-2 (Sigma) in IMDM with 10\%, 25\% or 50\% of human serum, for $15 \mathrm{~min}$ and then added to the SKOV3 cells. All samples were done in duplicate for Tcell proliferation measurement and as a single tryptophan and kynurenine measurement. After an incubation of $24 \mathrm{~h}$, the tryptophan and kynurenine concentrations in conditioned 
medium were assessed using LC-MS/MS. ${ }^{3} \mathrm{H}$-thymidine was added to the co-cultures for another $24 \mathrm{~h}$ incubation period. Thymidine incorporation was measured using a TopCount

counter (Perkin Elmer). Data were fitted and $\mathrm{EC}_{50}$ determined by using the Prism ${ }^{\mathrm{TM}}$ software (GraphPad software Inc.). $\mathrm{EC}_{50}$ was defined as the concentration at which PF06840003 half-maximally rescued human T-cell proliferation.

\section{Human Whole Blood Assay}

The assay was performed as previously described (21). Heparinized whole human blood was treated with LPS (25 $\mu \mathrm{g} / \mathrm{mL}$; Sigma, L-4391) and IFN $\gamma(100 \mathrm{ng} / \mathrm{mL}$; R\&D, 285-IF100). PF-06840003 was prepared in DMSO and added to individual $200 \mu \mathrm{L}$ blood aliquots in concentrations ranging from 0.01 to $100 \mu \mathrm{M}$. The total DMSO concentration was $0.5 \%$. After incubation for $20 \mathrm{~h}$ the samples were extracted with organic solvent. A $30 \mu \mathrm{l}$ aliquot was precipitated with $270 \mu \mathrm{l}$ acetonitrile/HPLC water (70:30), vortexed and centrifuged at $3,220 \mathrm{x} \mathrm{g}$ for $15 \mathrm{~min}$ at $10^{\circ} \mathrm{C}$. An aliquot of the supernatant organic solution was diluted in $0.1 \%$ formic acid and spiked with stable labeled isotopes of kynurenine and tryptophan as internal standards prior to analysis. PF-06840002, PF06840003, and kynurenine were measured using a triple quadrupole mass spectrometer. The $\mathrm{IC}_{50}$ and $\mathrm{IC}_{90}$ calculations were conducted in GraphPad Prism.

\section{In Vivo Experiments}

Female BALB/c and C57BL/6 mice (aged 6-8 weeks) were purchased from Charles River or The Jackson Laboratory. Tumor cells were implanted subcutaneously in PBS;

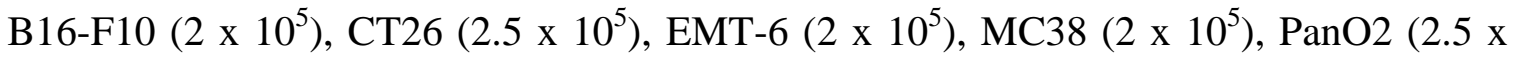
$\left.10^{6}\right)$, Renca $\left(10^{6}\right) .4 \mathrm{~T} 1\left(10^{5}\right)$ cells were implanted in PBS and MDA-MB-231 $\left(5 \times 10^{6}\right)$ cells suspended in serum-free media mixed with matrigel (Corning Life Sciences, Bedford, MA) were implanted into mammary fat pads. Mice were randomized into treatment groups based on tumor size. The experimenters were not blinded to the group assignment during the study and when assessing the outcome. Tumors were measured three times per week. Tumor volume was calculated based on two-dimensional caliper measurement as $0.5 \times$ length $\times$ width $^{2}$. Tumor growth inhibition (TGI) was determined by 
the formula: $\% \mathrm{TGI}=\left[1-\left(\mathrm{Vt}_{\mathrm{x}}-\mathrm{Vt}_{0} / \mathrm{Vc}_{\mathrm{x}}-\mathrm{Vc}_{0}\right)\right] \times 100$, where $\mathrm{Vc}, \mathrm{Vt}$ are the geometric means of control and treated group, respectively. $\mathrm{X}=$ day $\mathrm{X}$ on study and $0=$ initial day of dosing. Isolated plasma or tumor tissue was assessed by the Pfizer Pharmacokinetics, Dynamics and Metabolism Department for exposures. Anti-PD-L1 (clone 10F.9G2), antiCTLA4 (clone 9D9) and anti-CD8 (clone YTS 169.4) mAbs were purchased from BioXCell. Antibodies were dosed intraperitoneally. PF-06840003 was resuspended in 0.5\% HPMC-E4M/0.25\% Tween-20/H2O (Methocel, Colorcon) and mice were treated QD, BID, or TID by oral gavage. All procedures performed on these animals were in accordance with regulations and established guidelines and were reviewed and approved by Pfizer's Institutional Animal Care and Use Committee. Animals were sacrificed when the tumor size reached $>2000 \mathrm{~mm}^{3}$. The EMT6 model study was conducted at CrownBioTaicang. Humanized NOD-scid IL2 $\gamma^{\text {null }}\left(\mathrm{NSG}^{\mathrm{TM}}\right)$ mice were generated as previously described (22). Engrafted $\mathrm{Hu}-\mathrm{NSG}^{\mathrm{TM}}$ mice from different HSC donors were randomized independently and assigned into each treatment group. All animal procedures were carried out according to guidelines established by the Institutional Animal Care and Use Committee at Jackson Laboratories.

\section{Analysis of Tumor-Infiltrating Immune Cells and Splenocytes}

$24 \mathrm{~h}$ after the third antibody treatment, tumor single cell suspensions were generated with the mouse tumor dissociation kit (Miltenyi) following the manufacturer instructions. Tumor-infiltrating immune cells were enriched by gradient centrifugation on Lymphopre and washed in PBS. Cells were treated $3 \mathrm{~h}$ in presence of PMA, Ionomycin, Brefeldin A and Monensin according to the manufacturer's protocol (Cell Stimulation Cocktail, eBioscience). Cells were placed overnight at $4^{\circ} \mathrm{C}$ and stained using Livid dye (Life Technologies). Fc receptors were blocked by incubation with Fc Block (eBiosciences). APCeFluor780-conjugated anti-mouse CD45 (30F11), FITC-conjugated anti-mouse CD4 (RM4-5), PECy7-conjugated anti-mouse CD8a (53-6.7), APC-conjugated anti-mouse IFN-gamma (XMG1.2), and Cell Stimulation Cocktail kit were obtained from eBiosciences. Flow cytometry was performed on a MACSQuant (Miltenyi) and data were analysed with FlowJo (BD). 


\section{Results}

\section{Enzymatic Activity and IDO1 Specificity}

PF-06840003 is a racemic mixture of active (PF-06840002) and inactive (PF-06840001) enantiomers, which spontaneously epimerize to each other in plasma (Fig. 1A and B). After incubation of pure PF-06840002 in plasma in vitro, a significant amount of PF06840002 is converted to PF-06840001 in the first 6 hours in all of the three species tested ( $\sim 65 \%$ in humans, $42 \%$ in dogs and $34 \%$ in mice). Equilibration is achieved in 6 hours in humans, but delayed in dogs and mice (19). Based on this low inter-conversion barrier, the racemic mixture PF-06840003 rather than pure active enantiomer PF06840002 was used in the in vivo experiments described below.

Using a mass spectrometry (MS)-based enzymatic assay, $\mathrm{IC}_{50}$ values for PF-06840003 were similar for $\operatorname{dog}(0.59 \mu \mathrm{M})$ and human $(0.41 \mu \mathrm{M})$ IDO1 enzyme forms (Table 1$)$. PF06840003 was however 3.8 times more potent for the human enzyme compared with mouse IDO1 ( $\mathrm{IC}_{50}$ values of $0.4 \mu \mathrm{M}$ versus $1.5 \mu \mathrm{M}$, respectively). For the active enantiomer PF-06840002, $\mathrm{IC}_{50}$ values were similar for dog and human $(0.20 \mu \mathrm{M}$ versus $0.20 \mu \mathrm{M}$, respectively) while the inhibition of the human enzyme was 3.7 times more potent than mouse $(0.20 \mu \mathrm{M}$ versus $0.73 \mu \mathrm{M})$. Up to $10 \mu \mathrm{M}$ of PF-06840001, the inactive enantiomer, showed no IDO1 inhibition of the human enzyme. In the enzymatic MS assay, neither PF-06840003 nor PF-06840002 (active) were competitive with tryptophan for binding to either dog or human IDO1. We conclude that PF-06840002 is the enantiomer that actively inhibits IDO1 catalytic function in a non-competitive manner with the substrate tryptophan, while PF-06840001 (inactive) is not a catalytic IDO1 inhibitor.

\section{PF-06840003 Activity in Cellular Assays}

IDO1 is not constitutively expressed in many cell lines, but can be induced by treatment with pro-inflammatory cytokines, such as IFN $\gamma$ (23). This is analogous to the induction of IDO1 by inflammatory cues in the tumor microenvironment (24). PF-06840003 inhibited IFN $\gamma$-induced IDO1 cellular activity, resulting in reduced kynurenine production in both HeLa cervical carcinoma and monocytic THP-1 cells (Table 1).

As expected, the PF-06840003 racemate $\left(\mathrm{IC}_{50}=1.8 \mu \mathrm{M}\right.$ in HeLa, $1.7 \mu \mathrm{M}$ in THP-1) was 
less potent than the active enantiomer PF-06840002 $\left(\mathrm{IC}_{50}=1.0 \mu \mathrm{M}\right.$ in $\mathrm{HeLa}, 1.1 \mu \mathrm{M}$ in THP-1) in both cellular models. The inactive enantiomer PF-06840001 was much less active in both cellular assays $\left(\mathrm{IC}_{50}=12.8 \mu \mathrm{M}\right.$ and $5.8 \mu \mathrm{M}$, respectively). Its measured activity likely reflects racemization to the active enantiomer in culture over time. The inhibition of cellular IDO1 activity in these studies was not due to a reduction in cell viability (Supplementary Fig. S1).

To better determine the relative potencies of IDO1 inhibition in humans for racemic PF06840003 versus active enantiomer PF-06840002, we set up a human whole blood ex vivo pharmacodynamic stimulation assay. Whole blood samples were treated with LPS and IFN $\gamma$ to induce IDO1. The $\mathrm{IC}_{50} \mathrm{~S}$ found were $4.7 \pm 2.5 \mu \mathrm{M}$ for PF-06840003, and 2.5 $\pm 1.6 \mu \mathrm{M}$ for total PF-06840002 (Table 1). This corresponds to an adjusted unbound fraction $\mathrm{IC}_{50}$ of $1.1 \pm 0.7 \mu \mathrm{M}$, since PF-06840002 has a high fraction unbound (fu) of 0.45. A summary of plasma protein binding and blood to plasma ratios is shown in Supplementary Table 1.

\section{PF-06840003 is a Selective IDO1 Inhibitor}

Next, we assessed whether PF-06840003 is selective for IDO1 over TDO2 and IDO2, the other two enzymes involved in tryptophan catabolism. PF-06840003, PF-06840002 (active), and PF-06840001 (inactive) were evaluated in recombinant TDO2 and IDO2 enzymatic assays and did not display any significant inhibitory activity towards mouse or human enzymes based on kynurenine production (Table 1).

In addition, we tested whether PF-06840003 inhibits TDO2 by assessing kynurenine production in three different TDO2-expressing cell lines. The human glioblastoma cell line A172 constitutively expresses TDO2, while in the human acute monocytic leukemia cell line THP1, TDO2 can be induced by treatment with PMA. The potential inhibition of murine TDO2 was evaluated in a P815 murine mastocytoma cell line transfected with a murine TDO2-expression plasmid. At concentrations up to $50 \mu \mathrm{M}, \mathrm{PF}-06840003 \mathrm{did}$ not display any significant inhibitory cellular activity towards human or mouse TDO2. Thus, PF-06840003 has strong selectivity for IDO1 among tryptophan catabolizing enzymes.

PF-06840003 was further evaluated for off-target pharmacological activity in a panel of 81 receptors, ion channels, transporters and enzymes in a CEREP wide ligand profile screen at a concentration of $200 \mu \mathrm{M}$. Results indicated that PF-06840003 is highly 
selective. In the initial screen, significant interactions where PF-06840003 elicited $>50 \%$ inhibition or agonism versus controls were limited to 3 targets (Supplementary Table S2). At $200 \mu \mathrm{M}$ melanocortin 2 receptor (functional antagonist; $\mathrm{Kb}=170 \mu \mathrm{M}$ ) showed $41 \%$ inhibition, the muscarinic $\mathrm{M} 1$ receptor (antagonist; $\mathrm{Kb}=9.6 \mu \mathrm{M}$ ) was $69 \%$ inhibited and monoamine oxidase A showed 51\% inhibition (Supplementary Table S2). Follow-up titration curves determined an $\mathrm{IC}_{50}=1.4 \mathrm{mM}$ for the melanocortin 2 receptor, an $\mathrm{IC}_{50}=$ $81 \mu \mathrm{M}$ for the muscarinic $\mathrm{M} 1$ receptor, and an $\mathrm{IC}_{50}=190 \mu \mathrm{M}$ for monoamine oxidase $\mathrm{A}$. Given the much lower $\mathrm{IC}_{50}$ s for IDO1 inhibition, these results suggest a low potential for secondary (off-target) pharmacology at clinically relevant exposures. Further supporting its exquisite selectivity, PF-06840003 did not show off-target activity against the EMDMillipore KinaseProfiler ${ }^{\mathrm{TM}}$ panel of 270 kinases at $50 \mu \mathrm{M}$.

The potential for cardiovascular impact, specifically QT prolongation, was tested using the hERG assay. This assay showed less than a 50\% inhibition of the hERG channel up to $300 \mu \mathrm{M}$, the highest concentration tested. Genotoxicity risk was assessed by a bacterial reverse mutation assay (Ames Test), and an in vitro micronuclei test, the results of both tests were negative for genotoxicity (Supplementary Methods).

\section{PF-06840003 Rescues T-cell Proliferation in Co-Culture with Immunosuppressive Tumor Cells}

In vitro co-culture of IDO1-expressing SKOV3 tumor cells and T lymphocytes was established to mimic the physiological consequences of IDO1 expression in the tumor microenvironment on T-cell proliferation. Reduced T-cell proliferation in the presence of IDO1-positive tumor cells is used as a surrogate for the contribution of IDO1 to T-cell anergy in the tumor microenvironment. PF-06840003 effectively rescued IDO1-induced T-cell anergy in this assay with an $\mathrm{EC}_{50}$ of $80 \mathrm{nM}$ (Table 1; Supplementary Fig. S2A, B, and $\mathrm{C}$ ). $\mathrm{IC}_{50} \mathrm{~S}$ for inhibiting tryptophan to kynurenine conversion by SKOV3 cells in the same system were in the $\sim 100 \mathrm{nM}$ range (Supplementary Fig. S2D, E, and F), overall consistent with the values for overcoming T-cell inhibition. The ability of PF-06840003 to rescue $\mathrm{T}$-cell proliferation appeared to be serum-independent with $\mathrm{EC}_{50}$ values from 60 to $74 \mathrm{nM}$ in serum concentrations ranging from $10 \%$ to $50 \%$.

\section{PF-06840003 Inhibits IDO1 and Blocks L-kynurenine Formation in vivo}


Modulation of IDO1 activity by PF-06840003 in non-tumor bearing BALB/c mice was determined by measurement of its effects on plasma L-kynurenine and tryptophan concentrations over time. Mice were orally administered a single dose of PF-06840003 ranging from 20 to $1200 \mathrm{mg} / \mathrm{kg}$ (Fig. 1D; Supplementary Table S3). L-kynurenine and tryptophan plasma concentrations in female BALB/c control mice were $0.78 \pm 0.27 \mu \mathrm{M}$ and $90.7 \pm 20.3 \mu \mathrm{M}$, respectively (mean $\pm \mathrm{SD}, \mathrm{n}=65$ ). PF-06840003 administration caused a significant dose-dependent decrease of plasma L-kynurenine levels (Fig. 1C).

L-kynurenine reduction peaked at 1 hour post dose and correlated with concentrations of unbound active PF-06840002. A strong maximum reduction in plasma L-kynurenine $(\geq$ $54 \pm 6 \%$ ) was observed at or above $200 \mathrm{mg} / \mathrm{kg} 1$ hour post treatment. Based on the human whole blood assay and the 3.8-fold potency difference for inhibiting human versus mouse IDO1, the estimated in vivo $\mathrm{IC}_{50}$ and $\mathrm{IC}_{90}$ for free, unbound active PF06840002 against mouse IDO1 are $4 \mu \mathrm{M}$ and $21 \mu \mathrm{M}$, respectively.

Plasma L-kynurenine largely returned to or exceeded control levels by 24 hours post PF06840003 administration. Interestingly, maximally reduced L-kynurenine levels are comparable with the observed lower plasma concentrations in IDO1 knock-out mice (25). We thus conclude that PF-06840003 can achieve transient complete inhibition of IDO1 catalytic activity in mice following oral administration.

\section{Pharmacodynamics and Antitumor Activity of PF-06840003 in Syngeneic Mouse Tumor Models}

A panel of syngeneic mouse tumor models was characterized for basal and post-treatment levels of the IDO1 substrate tryptophan and metabolite L-kynurenine in plasma and tumor (Table 2). Tumor presence caused normal or slightly elevated systemic plasma kynurenine levels compared to basal plasma levels of $0.78 \pm 0.27 \mu \mathrm{M}$ kynurenine in $\mathrm{BALB} / \mathrm{c}$ and $1.05 \pm 0.28 \mu \mathrm{M}$ kynurenine in $\mathrm{C} 57 \mathrm{BL} / 6 \mathrm{~J}$ non-tumor bearing control mice. Kynurenine concentrations varied widely across the tumor panel, with highest levels in MC38 and CT26 syngeneic tumor recipients. IDO1 inhibition with PF-06840003 treatment effectively lowered plasma kynurenine levels in tumor bearing mice below basal levels. Similarly, a substantial reduction in kynurenine levels was achieved in tumor tissue across the panel (Table 2).

Next, we tested whether therapeutic IDO1 inhibition with PF-06840003 can suppress 
tumor growth across a panel of syngeneic models (PanO2, orthotopic 4T1, EMT6, Renca, B16-F10, CT26, MC38). We observed modest or transient tumor growth inhibition with PF-06840003 as a monotherapy (Fig. 2). No single agent benefit was observed in the EMT6 breast cancer model.

In the CT26 colon carcinoma model with high IDO1 activity, a dose range and different dosing schedules were evaluated (Fig. 3A). Reductions in plasma L-kynurenine levels $(\mathrm{p}<0.0001)$ were observed at all PF-06840003 treatment doses 3 hours post dosing, and were sustained over 6 hours. A dose-dependent range of reduction occurred with a maximal reduction by $81 \pm 14 \%$ at the highest dose (600 mg/kg BID). Tumor kynurenine levels were also significantly reduced $(\mathrm{p}<0.0001)$ at 3 and 6 hours post dosing with PF06840003 . Maximal reduction of $93 \pm 13 \%$ was achieved at the highest dose $(600 \mathrm{mg} / \mathrm{kg}$ BID) and sustained 3 and 6 hours post treatment. We observed comparable TGI with PF06840003 across the range of doses and dose schedules in the CT26 model (Supplementary Fig. S3).

Next, we tested whether the TGI with the IDO1 inhibitor PF-06840003 is immunemediated. In the absence of $\mathrm{CD}^{+} \mathrm{T}$ cells, IDO1 inhibition lost its impact on CT26 tumor growth (Supplementary Fig. S4).

\section{Antitumor Activity and Pharmacodynamics of PF-06840003 in Combination with Immune Checkpoint Inhibition}

Preclinical and clinical data both suggest that a greater anti-tumor benefit could be achieved when IDO1 inhibition is combined with immune checkpoint blockade $(26,27)$. Thus, much of the effort in the field has focused on identifying and validating various combination partners for IDO1 inhibition, such as antibodies that block PD-L1 (28). PDL1 and related PD-L2 are ligands for PD-1, a member of the CD28 superfamily of costimulatory or -inhibitory T-cell receptors that is mainly, but not exclusively, expressed on activated T-cells. PD-1 ligand engagement limits T-cell proliferation and cytokine production. This is a key mechanism mediating T-cell peripheral tolerance. PD-1 engagement facilitates tumor progression, while inhibition of PD-1 signaling may enhance tumor immune surveillance and foster anti-tumor immune responses (29).

In order to test the effectiveness of combination therapy, PF-06840003 treatment was tested in combination with avelumab, a fully humanized PD-L1 blocking immunoglobulin G1 antibody, in the CT26 colorectal cancer syngeneic model. As 
described earlier for PF-06840003 monotherapy, a significant reduction of about $80 \%$ total tumor L-kynurenine content was observed in mice co-administered avelumab and PF-06840003 (Fig. 3A). As a single agent, L-kynurenine modulation by PF-06840003 resulted in a TGI of $41 \%$ (Fig. 3B and C). The combination of PF-06840003 with avelumab caused an improved TGI benefit of 74\% (Fig. 3B and C).

Similar results were found for PF-06840003 combination with a rodent surrogate for the fully human avelumab, rat anti-mouse anti-PD-L1 mAb clone 10F.9G2 (Supplementary Fig. S5). When given as monotherapy, 10F.9G2 moderately delayed CT26 tumor growth. Combination of 10F.9G2 with PF-06840003 showed a significant benefit in inhibiting tumor growth vs. anti-PD-L1 alone (Supplementary Fig. S5).

Immuno-deficient mice engrafted with human $\mathrm{CD} 34^{+}$hematopoietic stem cells develop partial human immune systems that are responsive to checkpoint inhibition therapy (22). We tested the effectiveness of PF-06840003 against human IDO1 in humanized NSG mice bearing MDA-MB-231 breast tumors in two experiments using different human donors, as engrafting with $\mathrm{hCD}_{3} 4^{+}$cells from diverse donors recapitulates some of the heterogeneity in response of the patient population. (Supplementary Fig. S6 and S7). In both cases, PF-06840003 and anti-PD-L1 monotherapies achieved significant TGI. Combination of avelumab with PF-006840003 caused a modest benefit in inhibiting tumor growth vs. anti-PD-L1 alone (Supplementary Fig. S6 and S7).

\section{IDO1 Inhibitor PF-06840003 Combination with PD-L1 Blockade Increases IFN $\gamma$ - Secreting Tumor Infiltrating T-Cells}

We next analyzed how PF-06840003 monotherapy or combination with anti-PD-L1 antibody (clone 10F.9G2) may affect systemic versus tumor infiltrating immune cells. Proportions of granulocytic and monocytic MDSCs, $\mathrm{CD} 4^{+}, \mathrm{CD}^{+}$and regulatory T-cells were not significantly different between the treatment conditions in CT26 tumors (Supplementary Fig. S8). When T-cell activation was tested using an intracytoplasmic IFN $\gamma$ readout, PF-06840003 monotherapy did not induce any change in the proportion of IFN $\gamma$ secreting T-cells. In contrast, anti-PD-L1 monotherapy or combination with the IDO1 inhibitor was able to increase the proportion of splenic IFN $\gamma$ secreting $\mathrm{CD}^{+}$and $\mathrm{CD}^{+}$T-cells (Fig. 3D). Interestingly, the effect of anti-PD-L1 disappeared when tested on T-cells originating from the tumor microenvironment, suggesting the existence of a local immuno-suppressive mechanism. In this situation, only the combination of PF06840003 with anti-PD-L1 could induce a higher proportion of IFN $\gamma$ secreting T-cells 
that correlated with improved treatment efficacy (Fig. 3D). We conclude that IDO1 activity in the tumor microenvironment suppresses the induction of T-cell anti-tumor activity following anti-PD-L1 treatment.

\section{IDO1 and L-Kynurenine Levels are Increased in T-cell Immune Checkpoint Treated Tumors}

To test the hypothesis whether IDO1 may function as a resistance mechanism at the tumor site following treatment with an immune checkpoint inhibitor, we studied whether IDO1 activity was directly altered in anti-PD-L1 or anti-CTLA4 treated tumor bearing mice. Interestingly, kynurenine levels were significantly increased in MC38 and CT26 tumors after treatment with either anti-PD-L1 or anti-CTLA4, respectively (Fig. 4A and B), implying a direct link with IDO1 enzymatic activity. Next, we performed a Nanostring mRNA expression profile analysis in the MC38 mouse syngeneic colon tumor model. In the nCounter mouse Pancancer immune profiling panel, Pdcd1 (PD-1) and IDO1 transcripts were strongly increased in the anti-PD-L1 treatment group, while IDO1 inhibition alone had no significant impact on its mRNA level (Fig. 4C). This establishes a direct mechanistic link between $\mathrm{T}$-cell immune checkpoint inhibitor treatments in tumors with both the expression level and activity of IDO1 in the tumor microenvironment. Expression of the cytolytic enzyme granzyme A was increased after anti-PD-L1 + IDO1 inhibitor combination vs. anti-PD-L1 monotherapy (Fig. 4C). This implies enhanced and/or extended anti-tumor activity in the presence of IDO1 inhibition. Taken together, these data support the hypothesis that IDO1 acts as an induced resistance mechanism to treatments targeting the PD-1/PD-L1 immune checkpoint node and provide additional mechanistic rationale to combine checkpoint blocking therapeutics with an IDO1 inhibitor. 


\section{Discussion}

PF-06840003 is a novel orally bioavailable IDO1 inhibitor. We have demonstrated selective PF-06840003 inhibitory activity on murine, dog, and human IDO1, while the other two tryptophan metabolizing enzymes TDO2 and IDO2 are not inhibited at physiological concentrations of the drug. Inhibition of kynurenine production was also demonstrated in cervical carcinoma HeLa cells and in the THP-1 monocytic cell line. Exceptional selectivity for IDO1 and thus an overall low risk for off-target effects are further corroborated by CEREP wide ligand profile and kinase panel screens.

While the $\mathrm{IC}_{50}$ potency of the active enantiomer PF-06840002 in the enzymatic IDO1 assay does not reach the double digit nanomolar range of the first described catalytic IDO1 inhibitor INCB024360 (17,30), low plasma protein binding (Supplementary Table S1) coupled with favorable clearance and distribution characteristics provide a favorable human PK prediction for PF-06840002 (19).

We demonstrate that PF-06840003 is effective in modulating the Trp/Kyn balance in vitro and in vivo and able to rescue T-cell functions. Both tryptophan depletion and kynurenine metabolites have been described as important suppressors of T-cell function. T lymphocytes are sensitive to tryptophan shortage, which causes their arrest in the G1 phase of the cell cycle (5). This cell cycle arrest was proposed to depend on the induction of an integrated stress response triggered by the stress response kinase GCN2. GCN2 is activated by elevations in uncharged tRNAs, and phosphorylates eIF2a leading to inhibition of protein translation (6). Recent data however did not confirm the role of GCN2 (31). Tryptophan depletion may also inactivate the mTOR pathway, although this was not demonstrated in lymphocytes so far (8). Another proposed mechanism of IDO1mediated immune suppression involves the accumulation of tryptophan metabolites. 3hydroxyanthranilic and quinolinic acids can induce T-cell apoptosis $(10,32)$, while other kynurenine derivatives can induce the differentiation of regulatory T-cells (33). The aryl hydrocarbon receptor (AhR) may mediate these inhibitory properties of kynurenine derivatives (9). We have used systemic and intratumor L-kynurenine concentrations as the most proximal pharmacodynamic biomarker of IDO1 activity and inhibition by PF06840003, both in vitro and in vivo, and established a PK/PD relationship in mouse plasma. 
The characterization of a panel of commonly used syngeneic mouse tumors revealed a wide spread for basal L-kynurenine levels in tumors of untreated mice, with MC38 and CT26 having the highest basal L-kynurenine levels. Since the syngeneic tumors do not express TDO2 (34) and PF-06840003 treatment effectively lowered L-kynurenine levels, IDO1 activity appears responsible for immune suppressive tryptophan depletion and Lkynurenine generation in the murine tumor micro-environment.

Interestingly, the presence of mouse tumors did not result in a major significant systemic increase of L-kynurenine plasma concentrations across the syngeneic tumor panel vs. non-tumor bearing controls. In human patients with advanced cancer however, serum levels of L-kynurenine were found to be increased (17). This could be due to relatively higher IDO1 activity in human vs. mouse tumors and thus a more important role for IDO1 in suppressing the immune response against human tumors. PF-06840003 demonstrated an anti-tumor monotherapy benefit against established, randomized tumors in syngeneic tumor models, as well as in humanized mice bearing a human breast tumor. Tumor growth inhibition was modest in some syngeneic models with variable or transient individual tumor growth delay benefits across the treatment groups. We thus tested PF06840003 in a combination treatment setting, which holds higher promise for providing long lasting anti-tumor efficacy.

We show that following treatment with immune checkpoint modulators anti-CTLA4 and anti-PD-L1 tumor IDO1 activity was significantly increased. This provides additional mechanistic rationale for combining these therapeutics with an IDO1 inhibitor.

IDO1's inherent main biological function is to prevent or terminate excessive immune activation. IDO1 expression is up-regulated by type 1 and type 2 IFNs, which are frequently found at sites of inflammation (4). We show here that anti-CTLA4 therapy increased kynurenine production in CT26 tumors. Efficacy of anti-CTLA4 therapy was previously shown to be significantly increased in IDO1 knock-out mice (28). While IDO1 was proposed to be a resistance mechanism to anti-CTLA4 therapy with modulation of immune cell infiltrates (28), it had not been shown that anti-CTLA4 could directly increase IDO1-dependent kynurenine production in tumors. We also found that anti-PD-L1 therapy induced both IDO1 expression and function in MC38 tumors. This further supports the mechanistic rationale for the clinical combination of anti-PD-(L)1 treatments with IDO1 inhibitors. The induction of IDO1 expression by anti-CTLA4 and anti-PD-L1 is most likely indirect, resulting from T-cell activation which in turn induces secretion of IFN $\gamma$, a strong IDO1 inducer. 
The therapeutic benefit of combining anti-PD-(L)1 therapy with IDO1 inhibition was already shown in previous publications $(26,28)$. Holmgaard et al. used 1-MT, a noncatalytic activity targeting IDO1 pathway inhibitor, in their in vivo studies. Spranger et al. performed pharmacological studies with a potent IDO1 inhibitor derived from the clinical-stage compound INCB024360. Expanding beyond this work, our results help to understand the mechanism of action of the combination benefit of PF-06840003 and antiPD-L1 antibody in two tumor models. The in vivo anti-tumor efficacy of PD-L1 blockade was associated with an increase in IFN $\gamma$-positive tumor infiltrating lymphocytes. Interestingly, while anti-PD-L1 monotherapy induced a systemic increase in IFN $\gamma$ positive T-cells as observed in the spleen, this anti-PD-L1 effect was lost at the tumor site and could only be rescued by combining anti-PD-L1 with PF-06840003. PF-06840003 efficiently decreased the anti-PD-L1-induced kynurenine production. These data indicate that while anti-PD-L1 induces a systemic T-cell activation, immunosuppressive mechanisms present within the tumor microenvironment prevent the efficacy of immune checkpoint inhibitors at the tumor site. The observation that IFN $\gamma$ and IDO1 as well as kynurenine are induced within the tumor after treatment with anti-PD-L1 further confirm the activation of the IDO1 expression as a negative feedback loop of anti-PD-L1 immunotherapy. For these reasons, our data support that PF-06840003 can promote and maintain a tumor specific immune response by preventing IDO1-induced immunosuppressive mechanisms. Beyond our findings with anti-PD-L1, Monjazeb et al. have shown that several other immunotherapies such as IL-2, anti-CD40 or CpG are promoting IDO1 expression in tumors (35).

Our phenotyping of the tumor immune infiltrate has not revealed any modification of regulatory T-cells and myeloid-derived suppressor cells in PF-06840003-treated tumors (either in monotherapy or in combination with anti-PD-L1). The IDO1 inhibitor 1-MT was shown to modulate both effector and regulatory T-cells in various syngeneic tumor models $(28,36)$. Collective results obtained with potent and selective IDO1 inhibitors (PF-06840003 in this study, and the IDO1 inhibitor used by Spranger et al.) rather show and support a mechanism of action based on a marked increase of tumor-infiltrating effector T-cells. Given the relatively low potency of 1-MT to directly inhibit IDO1's catalytic activity (17), other mechanisms have been proposed such as mTOR pathway inactivation (8). The difference in the potency and selectivity profiles of the IDO1 inhibitors used might explain the above-described differences in mechanism of action between the three different studies. 
Beyond the preclinical data described here, PF-06840003 has a favorable predicted human PK profile. After oral administration of PF-06840003 to humans, the active enantiomer PF-06840002 has a predicted CLp of $0.64 \mathrm{ml} / \mathrm{min} / \mathrm{kg}$, Vss of $1.03 \mathrm{~L} / \mathrm{kg}$ and bioavailability of $64 \%$. CNS distribution was investigated in male rats. Unbound AUC ratios of brain to plasma and CSF to plasma of PF-06840002 (active) were 0.20 and 0.49 , and for PF-06840001 (inactive) were 0.21 and 0.56, respectively (19). These results indicate that CNS compartments are accessible to provide a promising treatment approach for brain metastases and glioblastoma with PF-06840003. 


\section{Acknowledgements}

We are grateful to Paul Rejto, Bob Abraham, Martin Edwards, Katti Jessen, James Hardwick, Kenneth Hook, James G. Keck, Jenny Chaplin, Jay Srirangam, Shibing Deng, Conglin Fan, Hui Wang, Karsten Sauer, Erick Kindt, Stephanie Shi, Tao Zhang, Michel Detheux, Coraline De Maeseneire, Kim Frederix, Julie Preillon and Pauline Bottemane for their generous support and helpful scientific discussions. 


\section{References}

1. Mahoney KM, Rennert PD, Freeman GJ. Combination cancer immunotherapy and new immunomodulatory targets. Nat Rev Drug Discov 2015;14(8):56184 doi 10.1038/nrd4591.

2. Iyer VV. Small molecules for immunomodulation in cancer: a review. Anticancer Agents Med Chem 2015;15(4):433-52.

3. Uyttenhove C, Pilotte L, Theate I, Stroobant V, Colau D, Parmentier N, et al. Evidence for a tumoral immune resistance mechanism based on tryptophan degradation by indoleamine 2,3-dioxygenase. Nat Med 2003;9(10):1269-74 doi 10.1038/nm934.

4. Mellor AL, Munn DH. IDO expression by dendritic cells: tolerance and tryptophan catabolism. Nat Rev Immunol 2004;4(10):762-74 doi 10.1038/nri1457.

5. Munn DH, Shafizadeh E, Attwood JT, Bondarev I, Pashine A, Mellor AL. Inhibition of $\mathrm{T}$ cell proliferation by macrophage tryptophan catabolism. J Exp Med 1999;189(9):1363-72.

6. Munn DH, Sharma MD, Baban B, Harding HP, Zhang Y, Ron D, et al. GCN2 kinase in $\mathrm{T}$ cells mediates proliferative arrest and anergy induction in response to indoleamine 2,3-dioxygenase. Immunity 2005;22(5):633-42 doi 10.1016/j.immuni.2005.03.013.

7. Bessede A, Gargaro M, Pallotta MT, Matino D, Servillo G, Brunacci C, et al. Aryl hydrocarbon receptor control of a disease tolerance defence pathway. Nature 2014;511(7508):184-90 doi 10.1038/nature13323.

8. Metz R, Rust S, Duhadaway JB, Mautino MR, Munn DH, Vahanian NN, et al. IDO inhibits a tryptophan sufficiency signal that stimulates mTOR: A novel IDO effector pathway targeted by D-1-methyl-tryptophan. Oncoimmunology 2012;1(9):1460-8 doi 10.4161/onci.21716.

9. Mezrich JD, Fechner JH, Zhang X, Johnson BP, Burlingham WJ, Bradfield CA. An interaction between kynurenine and the aryl hydrocarbon receptor can generate regulatory $\mathrm{T}$ cells. J Immunol 2010;185(6):3190-8 doi 10.4049/jimmunol.0903670.

10. Terness P, Bauer TM, Rose L, Dufter C, Watzlik A, Simon H, et al. Inhibition of allogeneic $\mathrm{T}$ cell proliferation by indoleamine 2,3-dioxygenase-expressing dendritic cells: mediation of suppression by tryptophan metabolites. J Exp Med 2002;196(4):447-57.

11. Okamoto A, Nikaido T, Ochiai K, Takakura S, Saito M, Aoki Y, et al. Indoleamine 2,3-dioxygenase serves as a marker of poor prognosis in gene expression profiles of serous ovarian cancer cells. Clin Cancer Res 2005;11(16):6030-9 doi 10.1158/1078-0432.CCR-04-2671.

12. Brandacher G, Perathoner A, Ladurner R, Schneeberger S, Obrist P, Winkler C, et al. Prognostic value of indoleamine 2,3-dioxygenase expression in colorectal cancer: effect on tumor-infiltrating $\mathrm{T}$ cells. Clin Cancer Res 2006;12(4):1144-51 doi 10.1158/1078-0432.CCR-05-1966. 
13. Godin-Ethier J, Hanafi LA, Piccirillo CA, Lapointe R. Indoleamine 2,3dioxygenase expression in human cancers: clinical and immunologic perspectives. Clin Cancer Res 2011;17(22):6985-91 doi 10.1158/10780432.CCR-11-1331.

14. van Baren N, Van den Eynde BJ. Tumoral Immune Resistance Mediated by Enzymes That Degrade Tryptophan. Cancer Immunol Res 2015;3(9):978-85 doi 10.1158/2326-6066.CIR-15-0095.

15. Platten M, von Knebel Doeberitz N, Oezen I, Wick W, Ochs K. Cancer Immunotherapy by Targeting ID01/TDO and Their Downstream Effectors. Front Immunol 2014;5:673 doi 10.3389/fimmu.2014.00673.

16. Beatty GL, O'Dwyer PJ, Clark J, Shi JG, Bowman KJ, Scherle PA, et al. First-inHuman Phase I Study of the Oral Inhibitor of Indoleamine 2,3-Dioxygenase-1 Epacadostat (INCB024360) in Patients with Advanced Solid Malignancies. Clin Cancer Res 2017;23(13):3269-76 doi 10.1158/1078-0432.CCR-162272.

17. Liu X, Shin N, Koblish HK, Yang G, Wang Q, Wang K, et al. Selective inhibition of ID01 effectively regulates mediators of antitumor immunity. Blood 2010;115(17):3520-30 doi 10.1182/blood-2009-09-246124.

18. Lob S, Konigsrainer A, Zieker D, Brucher BL, Rammensee HG, Opelz G, et al. ID01 and ID02 are expressed in human tumors: levo- but not dextro-1methyl tryptophan inhibits tryptophan catabolism. Cancer Immunol Immunother 2009;58(1):153-7 doi 10.1007/s00262-008-0513-6.

19. Crosignani S, Bingham $\mathrm{P}$, Bottemanne $\mathrm{P}$, Cannelle $\mathrm{H}$, Cauwenberghs $\mathrm{S}$, Cordonnier $\mathrm{M}$, et al. Discovery of a Novel and Selective Indoleamine 2,3Dioxygenase (ID0-1) Inhibitor 3-(5-Fluoro-1H-indol-3-yl)pyrrolidine-2,5dione (EOS200271/PF-06840003) and Its Characterization as a Potential Clinical Candidate. J Med Chem 2017;60(23):9617-29 doi 10.1021/acs.jmedchem.7b00974.

20. Pilotte L, Larrieu P, Stroobant V, Colau D, Dolusic E, Frederick R, et al. Reversal of tumoral immune resistance by inhibition of tryptophan 2,3dioxygenase. Proc Natl Acad Sci U S A 2012;109(7):2497-502 doi 10.1073/pnas.1113873109.

21. Newton RC, Scherle PA, Bowman K, Liu X, Beatty GL, O'Dwyer PJ, et al. Pharmacodynamic assessment of INCB024360, an inhibitor of indoleamine 2,3-dioxygenase 1 (ID01), in advanced cancer patients. Journal of Clinical Oncology 2012;30(15_suppl):2500- doi 10.1200/jco.2012.30.15_suppl.2500.

22. Wang M, Yao LC, Cheng M, Cai D, Martinek J, Pan CX, et al. Humanized mice in studying efficacy and mechanisms of PD-1-targeted cancer immunotherapy. FASEB J 2018:fj201700740R doi 10.1096/fj.201700740R.

23. Takikawa O, Kuroiwa T, Yamazaki F, Kido R. Mechanism of interferon-gamma action. Characterization of indoleamine 2,3-dioxygenase in cultured human cells induced by interferon-gamma and evaluation of the enzyme-mediated tryptophan degradation in its anticellular activity. J Biol Chem 1988;263(4):2041-8.

24. Muller AJ, Sharma MD, Chandler PR, Duhadaway JB, Everhart ME, Johnson BA, 3rd, et al. Chronic inflammation that facilitates tumor progression creates 
local immune suppression by inducing indoleamine 2,3 dioxygenase. Proc Natl Acad Sci U S A 2008;105(44):17073-8 doi 10.1073/pnas.0806173105.

25. Koblish HK, Hansbury MJ, Bowman KJ, Yang G, Neilan CL, Haley PJ, et al. Hydroxyamidine inhibitors of indoleamine-2,3-dioxygenase potently suppress systemic tryptophan catabolism and the growth of IDO-expressing tumors. Mol Cancer Ther 2010;9(2):489-98 doi 10.1158/1535-7163.MCT09-0628.

26. Spranger S, Koblish HK, Horton B, Scherle PA, Newton R, Gajewski TF. Mechanism of tumor rejection with doublets of CTLA-4, PD-1/PD-L1, or IDO blockade involves restored IL-2 production and proliferation of CD8(+) T cells directly within the tumor microenvironment. J Immunother Cancer 2014;2:3 doi 10.1186/2051-1426-2-3.

27. Gangadhar TC, Hamid O, Smith DC, Bauer TM, Wasser JS, Olszanski AJ, et al. Epacadostat plus pembrolizumab in patients with advanced melanoma and select solid tumors: Updated phase 1 results from ECHO-202/KEYNOTE-037. Annals of Oncology 2016;27(suppl_6):1110PD-PD doi 10.1093/annonc/mdw379.06.

28. Holmgaard RB, Zamarin D, Munn DH, Wolchok JD, Allison JP. Indoleamine 2,3-dioxygenase is a critical resistance mechanism in antitumor $\mathrm{T}$ cell immunotherapy targeting CTLA-4. J Exp Med 2013;210(7):1389-402 doi 10.1084/jem.20130066.

29. Chen L, Han X. Anti-PD-1/PD-L1 therapy of human cancer: past, present, and future. J Clin Invest 2015;125(9):3384-91 doi 10.1172/JCI80011.

30. Yue EW, Douty B, Wayland B, Bower M, Liu X, Leffet L, et al. Discovery of potent competitive inhibitors of indoleamine 2,3-dioxygenase with in vivo pharmacodynamic activity and efficacy in a mouse melanoma model. J Med Chem 2009;52(23):7364-7 doi 10.1021/jm900518f.

31. Sonner JK, Deumelandt K, Ott M, Thome CM, Rauschenbach KJ, Schulz S, et al. The stress kinase GCN2 does not mediate suppression of antitumor $\mathrm{T}$ cell responses by tryptophan catabolism in experimental melanomas. Oncoimmunology 10.1080/2162402X.2016.1240858.

32. Fallarino F, Grohmann U, Vacca C, Bianchi R, Orabona C, Spreca A, et al. T cell apoptosis by tryptophan catabolism. Cell Death Differ 2002;9(10):1069-77 doi 10.1038/sj.cdd.4401073.

33. Fallarino F, Grohmann U, You S, McGrath BC, Cavener DR, Vacca C, et al. The combined effects of tryptophan starvation and tryptophan catabolites downregulate $\mathrm{T}$ cell receptor zeta-chain and induce a regulatory phenotype in naive T cells. J Immunol 2006;176(11):6752-61.

34. Xing F, Qian W, Dong C, Xu X, Guo S, Shi Q. Abstract 5597: Genomic profiling of syngeneic mouse cell lines and $<$ em $>$ in vitro $</$ em $>$ screen of the models against checkpoint inhibitors and target agents for preclinical application. Cancer Research 2017;77(13 Supplement):5597- doi 10.1158/15387445.am2017-5597.

35. Monjazeb AM, Kent MS, Grossenbacher SK, Mall C, Zamora AE, Mirsoian A, et al. Blocking Indolamine-2,3-Dioxygenase Rebound Immune Suppression 
Boosts Antitumor Effects of Radio-Immunotherapy in Murine Models and Spontaneous Canine Malignancies. Clin Cancer Res 2016;22(17):4328-40 doi 10.1158/1078-0432.CCR-15-3026.

36. Holmgaard RB, Zamarin D, Li Y, Gasmi B, Munn DH, Allison JP, et al. TumorExpressed IDO Recruits and Activates MDSCs in a Treg-Dependent Manner. Cell Rep 2015;13(2):412-24 doi 10.1016/j.celrep.2015.08.077. 
Table 1. In vitro pharmacology of PF-06840003 and its enantiomers PF-06840002, PF06840001.

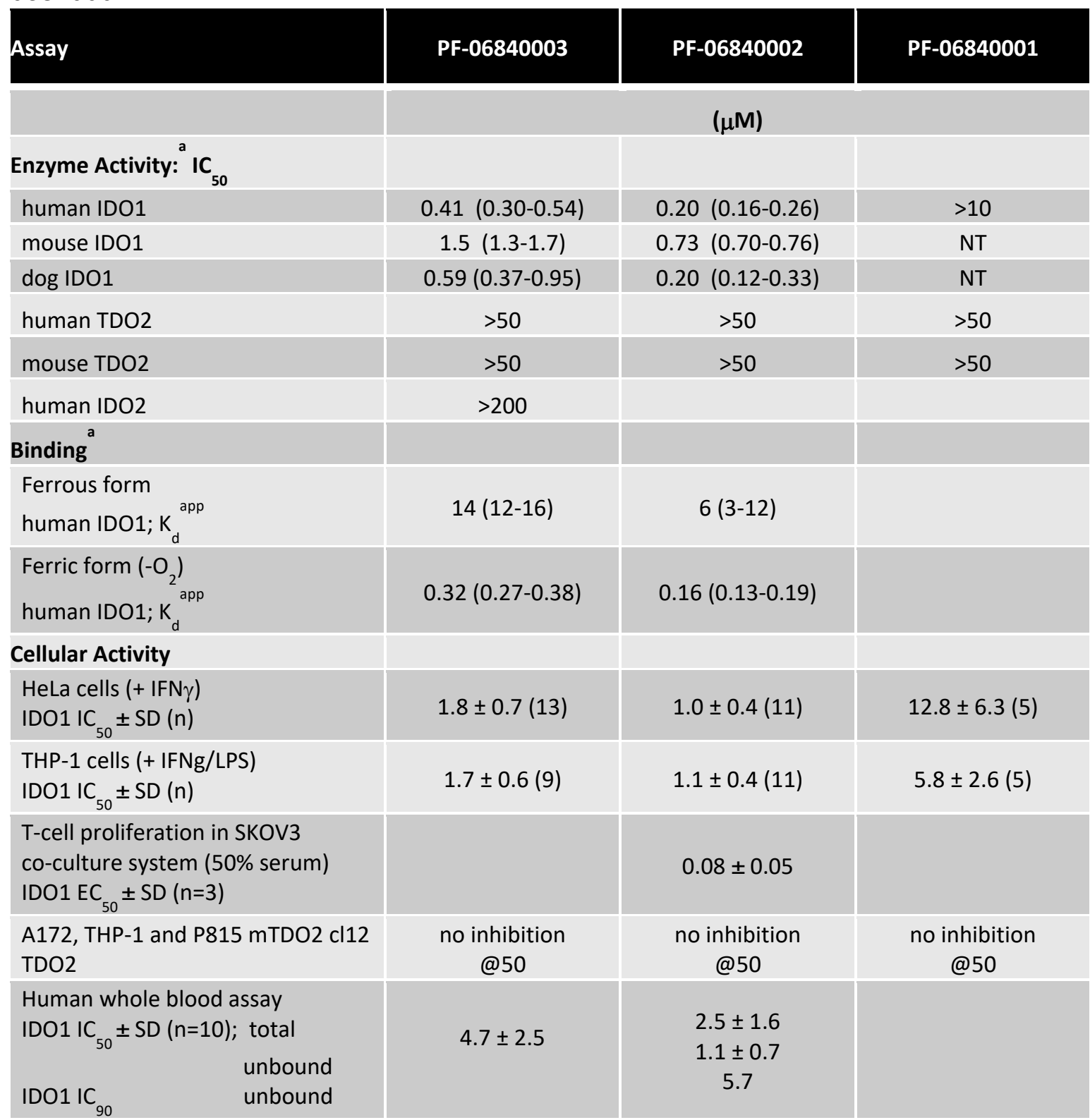

${ }^{\mathrm{a}}$ Data are represented as geometric mean in $\mu \mathrm{M}$, plus $95 \%$ confidence interval determined from 2 to 7 independent measurements

$\mathrm{Kd}^{\text {app }}$ Ferrous $=\mathrm{Kd}^{\text {app }}$ when test article is titrated into the ferrous form of IDO1; Kdapp Ferric $\left(+\mathrm{O}_{2}\right)=$ $\mathrm{Kd}^{\text {app }}$ when test article is titrated into the ferric form of IDO1 without measures to remove oxygen; Kd ${ }^{\text {app }}$ Ferric $\left(-\mathrm{O}_{2}\right)=\mathrm{Kd}^{\text {app }}$ when test article is titrated into the ferric form of IDO1 following oxygen depletion; $\mathrm{Kd}^{\text {app }}$ Ferric $\left(-\mathrm{O}_{2},+\mathrm{Trp}\right)=\mathrm{Kd}^{\text {app }}$ when test article is titrated into the ferric form of IDO1 following oxygen depletion in the presence of tryptophan; mIDO1 = Mouse IDO1 enzyme; NT = Not tested; $\mathrm{O}_{2}=$ Molecular oxygen; Trp = Tryptophan. 
Table 2. Kynurenine levels in syngeneic mouse tumors and plasma following anti-PDL1 administrations and at indicated times post PF-06840003 treatment.

\begin{tabular}{|c|c|c|c|c|c|c|c|}
\hline \multicolumn{2}{|c|}{ Tumor } & \multicolumn{6}{|c|}{ Kynurenine ( $\mu \mathrm{M})$} \\
\hline Tumor & Mouse & & & & & & \\
\hline \multirow{2}{*}{ Model } & \multirow{2}{*}{ Strain } & \multirow{2}{*}{ Control } & \multirow{2}{*}{ PD-L1 } & \multicolumn{2}{|c|}{ IDO1i } & \multicolumn{2}{|c|}{ PDL1 + IDO1i } \\
\hline & & & & 2 or $3 \mathrm{hr}$ & $6 \mathrm{hr}$ & 2 or $3 \mathrm{hr}$ & $6 \mathrm{hr}$ \\
\hline $\mathrm{CT}_{26}{ }^{1}$ & $B A L B / c$ & $11.12 \pm 6.21(n=25)$ & $16.04 \pm 5.35(n=12)^{*}$ & $\begin{array}{c}3 \mathrm{hr} \\
1.69 \pm 0.50(\mathrm{n}=11)^{* *}\end{array}$ & $1.43 \pm 0.56(n=11)^{* *}$ & $\begin{array}{c}3 \mathrm{hr} \\
*^{*} .52 \pm 1.20(\mathrm{n}=4)^{*}\end{array}$ & $1.91 \pm 0.84(n=4)^{* *}$ \\
\hline $\mathrm{MC}^{1}{ }^{1}$ & C57BL/6 & $3.23 \pm 1.41(\mathrm{n}=18)$ & $11.10 \pm 5.98(n=17)^{* *}$ & $\begin{array}{c}3 \mathrm{hr} \\
1.67 \pm 1.48(\mathrm{n}=8)^{*}\end{array}$ & $2.27 \pm 1.24(\mathrm{n}=8)$ & $\begin{array}{c}3 \mathrm{hr} \\
2.63 \pm 1.90(n=4)\end{array}$ & $2.34 \pm 1.40(n=4)$ \\
\hline $\mathrm{Pan02}^{2}$ & C57BL/6 & $2.40 \pm 1.11(\mathrm{n}=10)$ & $2.35 \pm 1.07(n=10)$ & $\begin{array}{c}3 \mathrm{hr} \\
0.67 \pm 0.49(n=5)^{* *}\end{array}$ & $2.23 \pm 1.13(n=5)$ & $\begin{array}{c}3 \mathrm{hr} \\
1.60 \pm 1.06(n=5)\end{array}$ & $0.92 \pm 0.58(n=5)^{*}$ \\
\hline $4 \mathrm{TI}^{1}$ & $B A L B / c$ & $1.82 \pm 1.31(n=40)$ & & $\begin{array}{c}3 \mathrm{hr} \\
0.82 \pm 0.59(n=13)^{*}\end{array}$ & $\begin{array}{c}8 \mathrm{hr} \\
0.91 \pm 0.66(n=15)^{*}\end{array}$ & & \\
\hline EMT6 ${ }^{1}$ & $B A L B / c$ & $1.01 \pm 0.42(n=5)$ & $0.93 \pm 0.29(n=4)$ & $\begin{array}{c}2 \mathrm{hr} \\
0.48 \pm 0.17(n=3)^{*}\end{array}$ & $0.55 \pm 0.17(\mathrm{n}=4)^{*}$ & $\begin{array}{c}2 \mathrm{hr} \\
0.36 \pm 0.03(n=3)^{*}\end{array}$ & $0.44 \pm 0.10(n=3)^{*}$ \\
\hline B16-F10 ${ }^{2}$ & C57BL/6 & $0.92 \pm 0.34(n=15)$ & $0.76 \pm 0.30(n=15)$ & $\begin{array}{c}2 \mathrm{hr} \\
0.49 \pm 0.09(\mathrm{n}=4)^{*}\end{array}$ & $0.42 \pm 0.15(\mathrm{n}=3)^{*}$ & $0.58 \pm 0.13(n=4)^{*}$ & $0.58 \pm 0.16(n=4)^{*}$ \\
\hline Renca $^{2}$ & $B A L B / c$ & $0.54 \pm 0.58(n=16)$ & $0.48 \pm 0.30(n=15)$ & $\begin{array}{c}2 \mathrm{hr} \\
0.16 \pm 0.06(n=3)\end{array}$ & & $\begin{array}{c}2 \mathrm{hr} \\
0.19 \pm 0.05(n=6)\end{array}$ & \\
\hline \multicolumn{2}{|c|}{ Plasma } & \multicolumn{6}{|c|}{ Kynurenine ( $\mu \mathrm{M})$} \\
\hline Tumor & Mouse & Control & PD-L1 & IDC & & PDL1+ & + IDO1i \\
\hline Model & Strain & & & 2 or $3 \mathrm{hr}$ & $6 \mathrm{hr}$ & 2 or $3 \mathrm{hr}$ & $6 \mathrm{hr}$ \\
\hline None & $\mathrm{BALB} / \mathrm{c}$ & $0.78 \pm 0.27(n=65)$ & & & & & \\
\hline None & C57BL/6J & $1.05 \pm 0.28(\mathrm{n}=30)$ & & & & & \\
\hline ст $26^{1}$ & $B A L B / C$ & $1.12 \pm 0.63(n=25)^{\# \#}$ & $1.28 \pm 0.42(n=12)$ & $\begin{array}{c}3 \mathrm{hr} \\
0.34 \pm 0.09(\mathrm{n}=11)^{* *}\end{array}$ & $0.35 \pm 0.06(n=11)^{* *}$ & $\begin{array}{c}3 \mathrm{hr} \\
0.31 \pm 0.08(n=4)^{*}\end{array}$ & $0.40 \pm 0.10(n=4)^{*}$ \\
\hline MC38 ${ }^{1}$ & C57BL/6 & $1.10 \pm 0.36(\mathrm{n}=18)^{\mathrm{ns}}$ & $1.38 \pm 0.61(n=17)^{*}$ & $\begin{array}{c}3 \mathrm{hr} \\
0.48 \pm 0.13(n=8)^{* *}\end{array}$ & $0.51 \pm 0.18(n=8)^{* *}$ & $\begin{array}{c}3 \mathrm{hr} \\
0.61 \pm 0.13(\mathrm{n}=4)^{* *}\end{array}$ & $0.73 \pm 0.29(n=4)^{*}$ \\
\hline $\mathrm{Pan02}^{2}$ & C57BL/6 & $0.92 \pm 0.15(\mathrm{n}=10)^{\mathrm{ns}}$ & $1.00 \pm 0.19(n=10)$ & $\begin{array}{c}3 \mathrm{hr} \\
0.36 \pm 0.13(\mathrm{n}=5)^{* *}\end{array}$ & $0.48 \pm 0.14(n=5)^{* *}$ & $\begin{array}{c}3 \mathrm{hr} \\
0.48 \pm 0.25(n=5)^{* *}\end{array}$ & $0.48 \pm 0.28(n=5)^{* *}$ \\
\hline $4 \mathrm{TI}^{1}$ & $B A L B / C$ & $0.85 \pm 0.21(n=25)^{n s}$ & & $\begin{array}{c}3 \mathrm{hr} \\
0.44 \pm 0.12(\mathrm{n}=10)^{* *}\end{array}$ & $\begin{array}{c}8 \mathrm{hr} \\
0.56 \pm 0.10(\mathrm{n}=5)^{* *}\end{array}$ & & \\
\hline EMT6 $^{1}$ & $B A L B / c$ & $1.01 \pm 0.29(n=5)^{\#}$ & $1.01 \pm 0.39(n=4)$ & $\begin{array}{c}2 \mathrm{hr} \\
0.57 \pm 0.22(n=3)^{*}\end{array}$ & $0.58 \pm 0.23(n=4)^{*}$ & $\begin{array}{c}2 \mathrm{hr} \\
0.33 \pm 0.01(n=3)^{* *}\end{array}$ & $0.57 \pm 0.11(n=3)^{*}$ \\
\hline $\mathrm{B} 16-\mathrm{F} 10^{2}$ & C57BL/6 & $0.94 \pm 0.32(\mathrm{n}=15)^{\mathrm{ns}}$ & $0.75 \pm 0.21(n=15)$ & $\begin{array}{c}2 \mathrm{hr} \\
0.32 \pm 0.04(n=4)^{* *}\end{array}$ & $0.39 \pm 0.03(n=3)^{*}$ & $0.37 \pm 0.10(n=4)^{* *}$ & $0.56 \pm 0.09(n=4)^{*}$ \\
\hline Renca $^{2}$ & $B A L B / C$ & $0.92 \pm 0.26(n=16)^{\#}$ & $0.84 \pm 0.27(n=15)$ & $\begin{array}{c}2 \mathrm{hr} \\
0.19 \pm 0.03(\mathrm{n}=3)^{* *}\end{array}$ & & $\begin{array}{c}2 \mathrm{hr} \\
0.29 \pm 0.11(n=6)^{* *}\end{array}$ & \\
\hline
\end{tabular}

Mean \pm SD is shown. ${ }^{1}$ Mice were treated with $200 \mathrm{mg} / \mathrm{kg}$, BID of PF-06840003. ${ }^{2}$ Mice were treated with $600 \mathrm{mg} / \mathrm{kg}$, BID of PF-06840003.*, $P<0.05 ; * *, P<0.005$ by unpaired Student $t$ test vs. control. $, P<0.05,^{\#} ; P<0.005$; ns, not significant $(P>0.05)$ by unpaired Student $t$ test vs. respective non-tumor bearing mouse strain control. 


\section{Figure Legends}

Figure 1. PF-06840003: Structure + Racemate.

A. Structure of PF-06840003 and its enantiomers PF-06840002 and PF-06840001.

B. In vitro chiral inter-conversion. PF-06840003 is a racemate that equilibrates quickly in mouse plasma between PF-06840002, the active IDO1 inhibitor and PF-06840001, which lacks the capacity to inhibit IDO1. Similar data were obtained in human and dog plasma (21). Data represent a triplicate analysis, mean \pm SD shown.

C. Correlation of plasma Kyn levels with PF-06840002 exposure in female BALB/c mice following a single oral dose of PF-06840003 as detailed in Supplementary Table S1. A four-parameter logistic equation with upper limit equal to $0.78 \mu \mathrm{M}$ (baseline Kyn in untreated mice), lower limit equal to $0.24 \mu \mathrm{M}$ (average Kyn level when free PF$06840002>50 \mu \mathrm{M}$ ), and Hill coefficient equal to 1.3 (determined from the human whole blood assay) was used to estimate an in vivo $\mathrm{IC}_{50}$ of $5.2 \mu \mathrm{M}$ (dashed line).

D. Mean plasma concentration vs. time of PF-06840002 following oral administration of $\mathrm{PF}-06840003$ in female $\mathrm{BALB} / \mathrm{c}$ mice. The mouse $\mathrm{IDO} 1 \mathrm{IC}_{50}$ and $\mathrm{IC}_{90}$ values extrapolated from the human whole blood assay (Table 1) are shown for reference. Error bars represent standard deviation.

Figure 2. IDO1 inhibition demonstrates significant anti-tumor growth benefit as monotherapy in syngeneic tumor models (ANCOVA). Mice were randomized into groups based on established tumor volume and PF-06840003 treatment was initiated on the day post implantation as shown for each tumor model in the graphs. No single agent IDO1 inhibitor anti-tumor efficacy was observed in the EMT6 breast model.

Figure 3. Combinatorial IDO1i + avelumab (anti-PD-L1) treatment in the subcutaneous CT26 syngeneic mouse colon tumor model.

A. PD modulation in CT26 tumors: Reduction of elevated Kyn levels in tumor tissue serves as a proximal PD biomarker for PF-06840003 mediated IDO1 inhibition. Plasma and tumor L-kynurenine and tryptophan concentrations were analyzed at 3 and 6 hours post the final dose. Plasma Kyn level in non-tumor bearing BALB/c mice is indicated by the grey dotted line. Statistical analysis: ANCOVA. 
B. Tumor growth inhibition in mice. $n=10$ per group, randomization and treatment start on day 9 after tumor implant. Statistical analysis: ANCOVA.

C. Individual tumor growth curves.

D. Increase of $\mathrm{CD}^{+} \mathrm{IFN}^{+}$and $\mathrm{CD} 8^{+} \mathrm{IFN} \gamma^{+} \mathrm{T}$-cells in $\mathrm{CT} 26$ tumors following combined anti-PD-L1 and PF-06840003 treatment. The proportion of splenic and intra-tumoral $\mathrm{CD}^{+}{ }^{+} \mathrm{IFN} \gamma^{+}$and $\mathrm{CD} 8^{+} \mathrm{IFN} \gamma^{+}$T-cells after 10 days of continuous PF-0684003 $(200 \mathrm{mg} / \mathrm{kg}$, BID) treatment and 3 doses of anti-PD-L1 (10 mg/kg; Q3D; clone 10F.9G2) is shown. Cells were stimulated for $3 \mathrm{~h}$ in the presence of PMA/Iono/Brefeldin A. Line indicates the median. Statistical analysis is based on a 2-way ANOVA test. $n=8$ per group. Representative data of two independent experiments are shown.

Figure 4. Anti-PD-L1 and anti-CTLA4 induces IDO1 activity as demonstrated in elevated Kyn levels in plasma and tumor tissue.

A. PF-06840003 effectively suppresses anti-CTLA4 induced elevated Kyn levels in CT26 tumors. 4 hours past PF-06840002 dosage (100 mg/kg, BID).

B. Elevated IDO1 activity / Kyn level in MC38 tumors following anti-PD-L1 (10F9G2) treatment. IDO1 inhibition counteracts the anti-PD-L1 driven up-regulation of IDO1 activity demonstrated in lowered Kyn levels. ( $n=10$ or 5; geomean shown; tumors were harvested on day 14 of treatment 3 or 7 hours post last IDO1i treatment.

C. Increase of overall IDO1 expression in MC38 tumors after anti-PD-L1 treatment. Tumors $(n=3)$ were analyzed by nanostring technology on day 24 for quantification of gene expression transcript levels with the nCounter mouse Pancancer immune profiling panel. $\mathrm{P}$ values were calculated by one-way ANOVA analysis. 
A

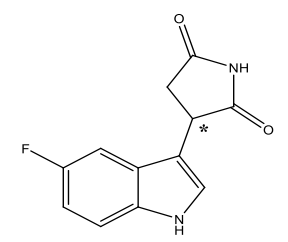

PF-06840003

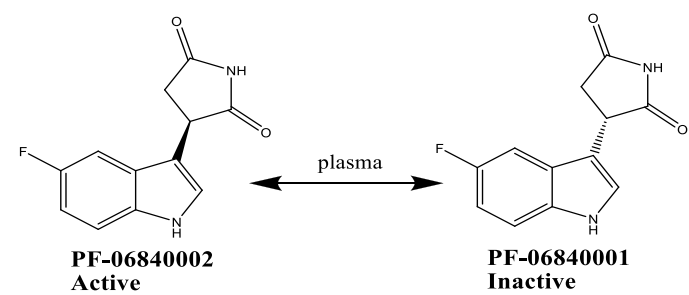

Active
B

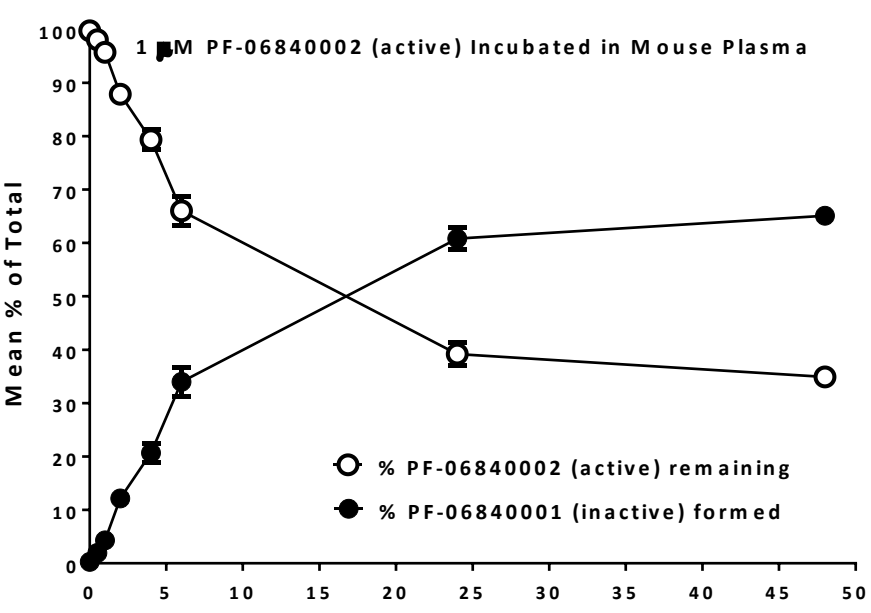

Time (hr)

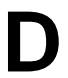

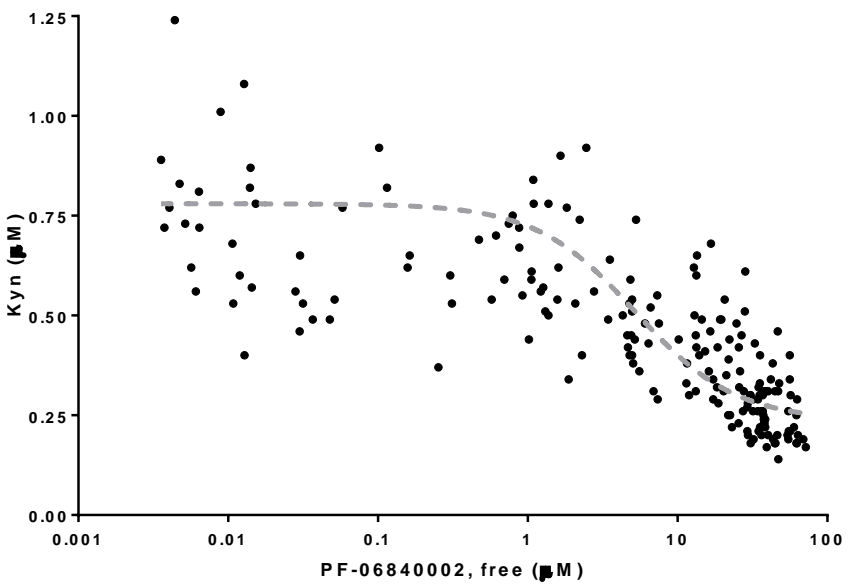

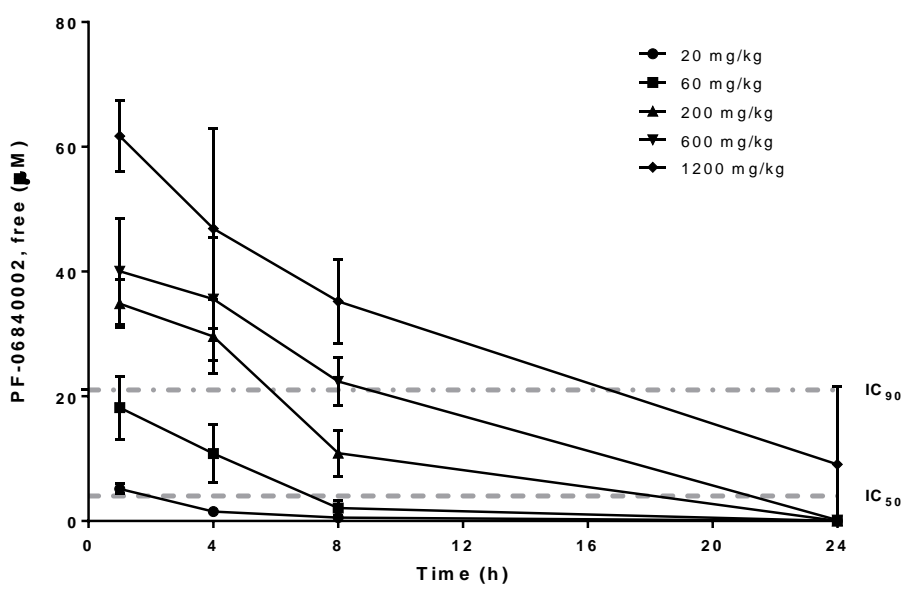

Figure 1. 

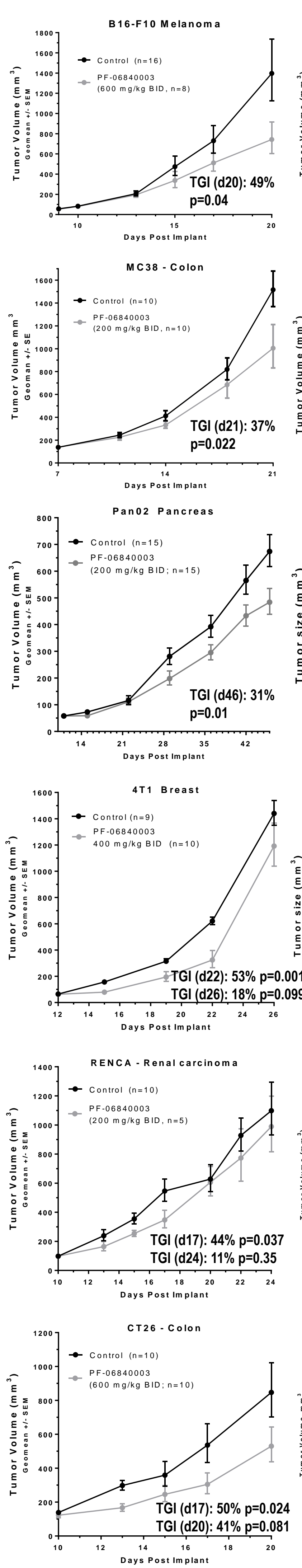

EM T6 - Breast

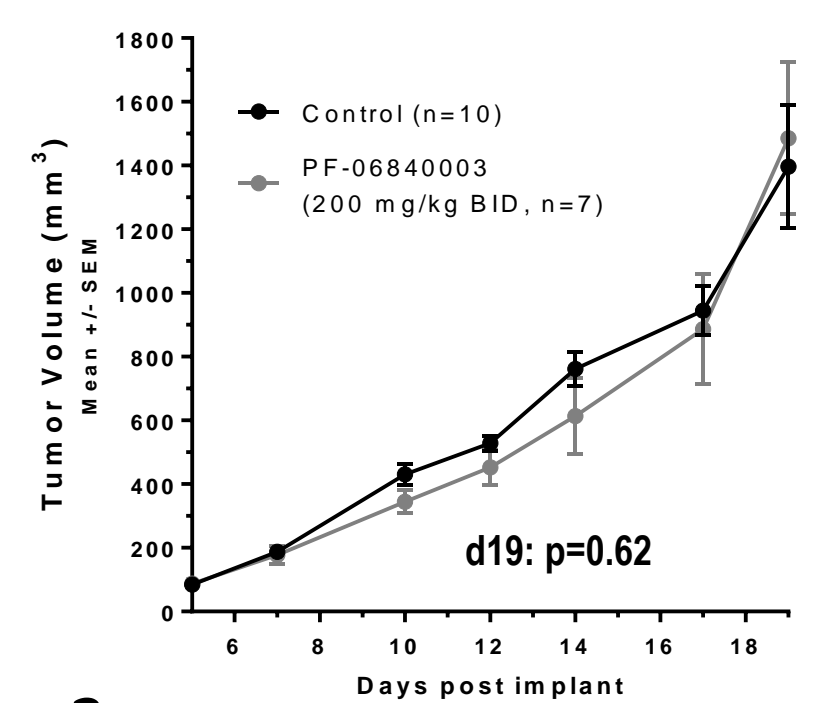

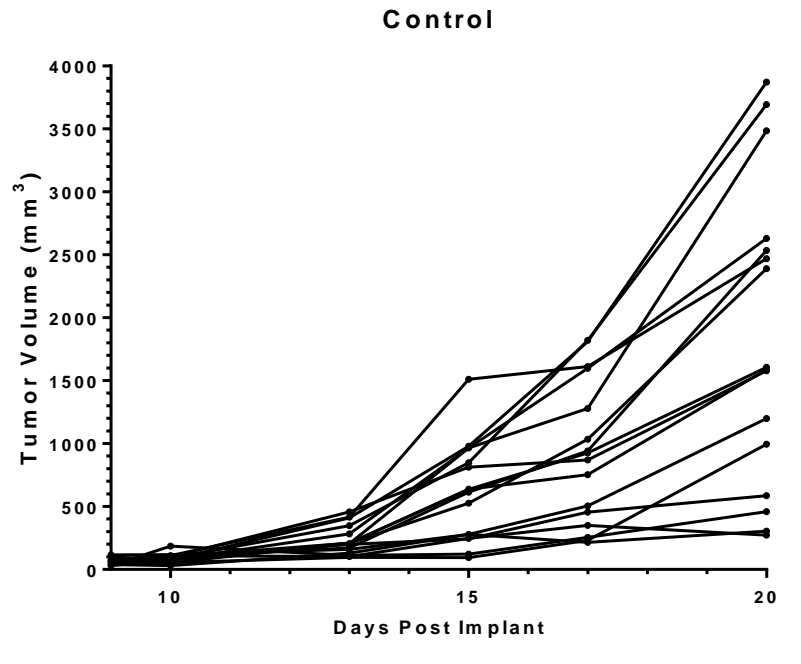

Control
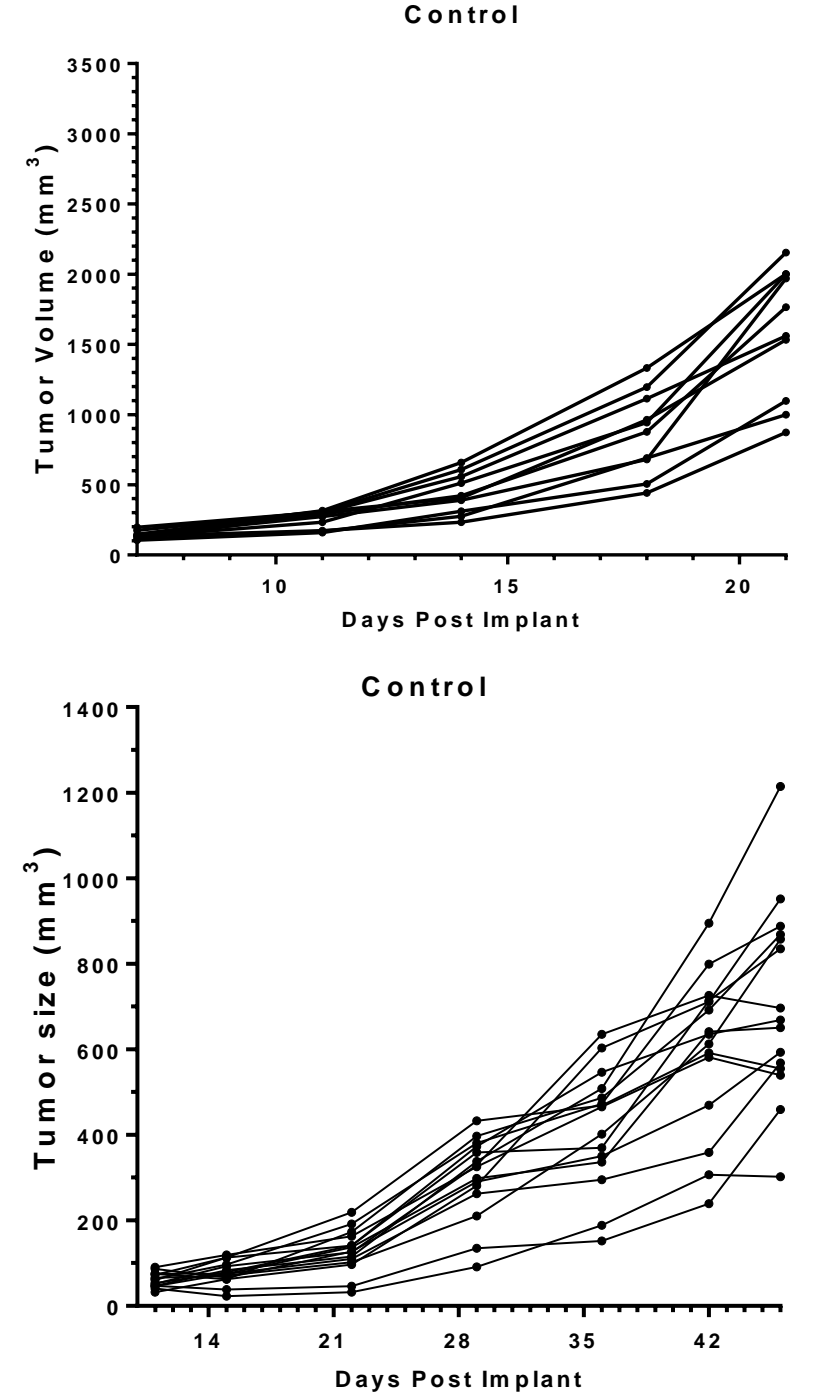

control
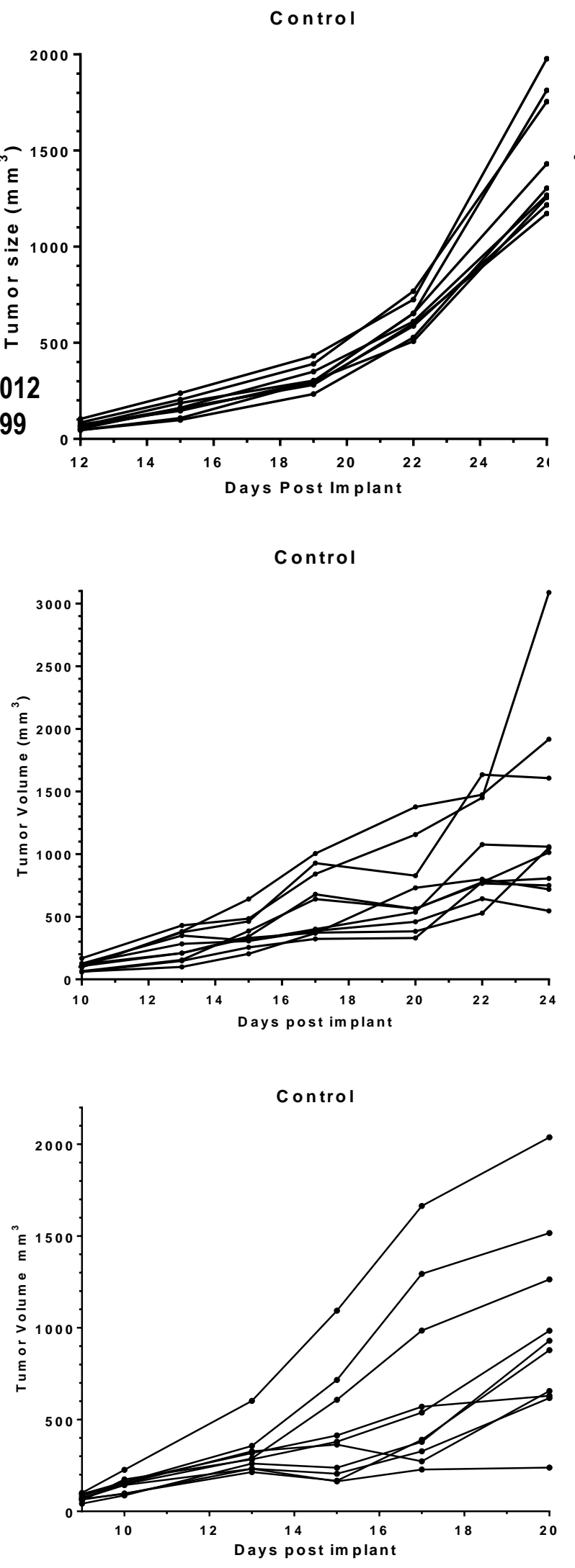

Control

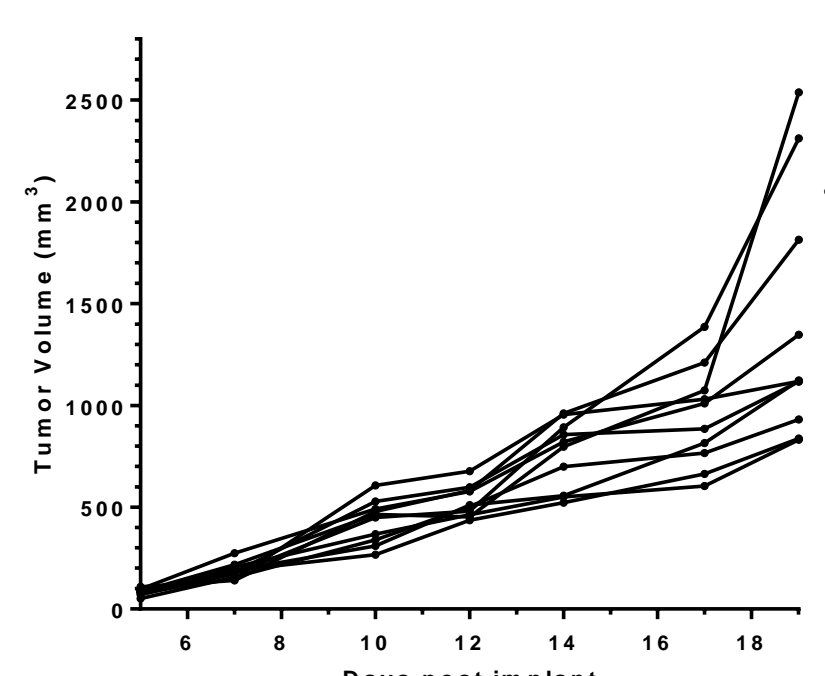

DO $1(600 \mathrm{mg} / \mathrm{kg} \mathrm{BID})$
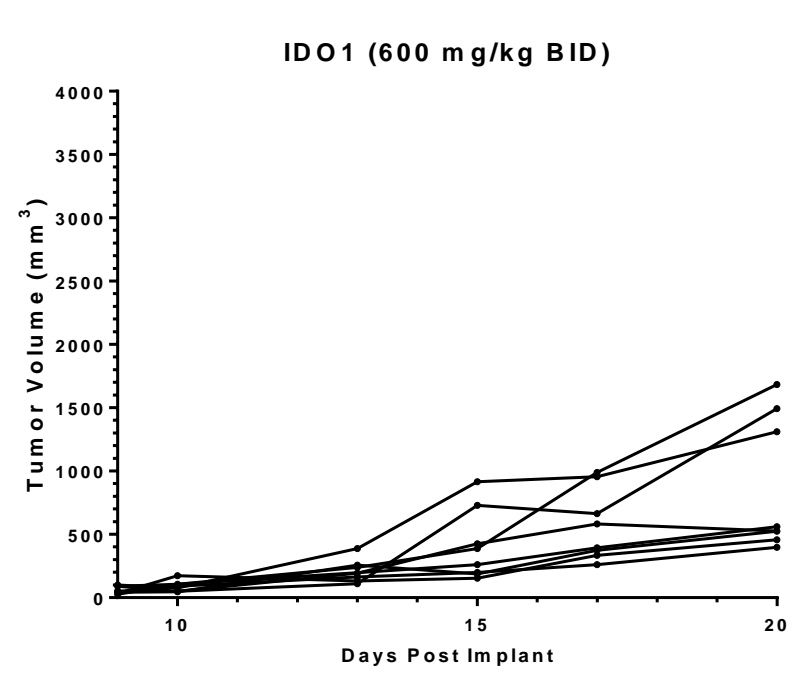

IDO1 (200 m g/kg BID)

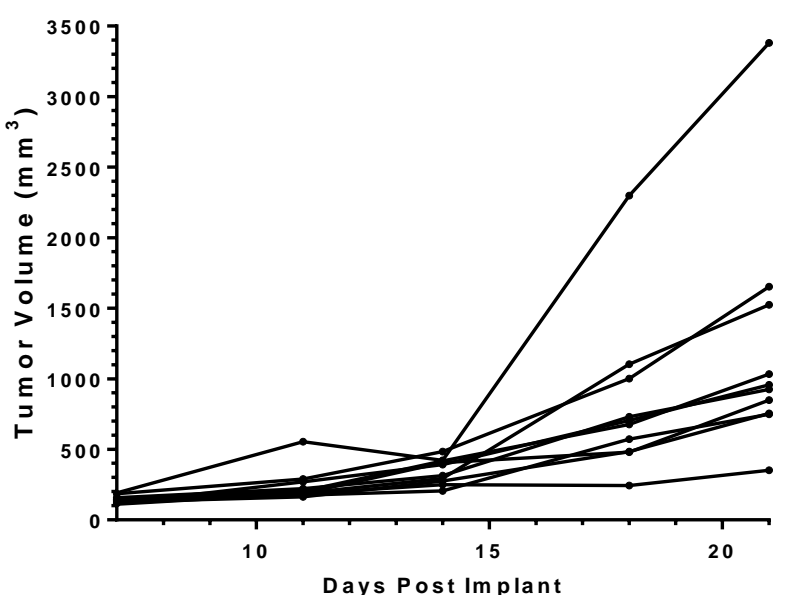

IDO $1(200 \mathrm{mg} / \mathrm{kg} \mathrm{BID})$

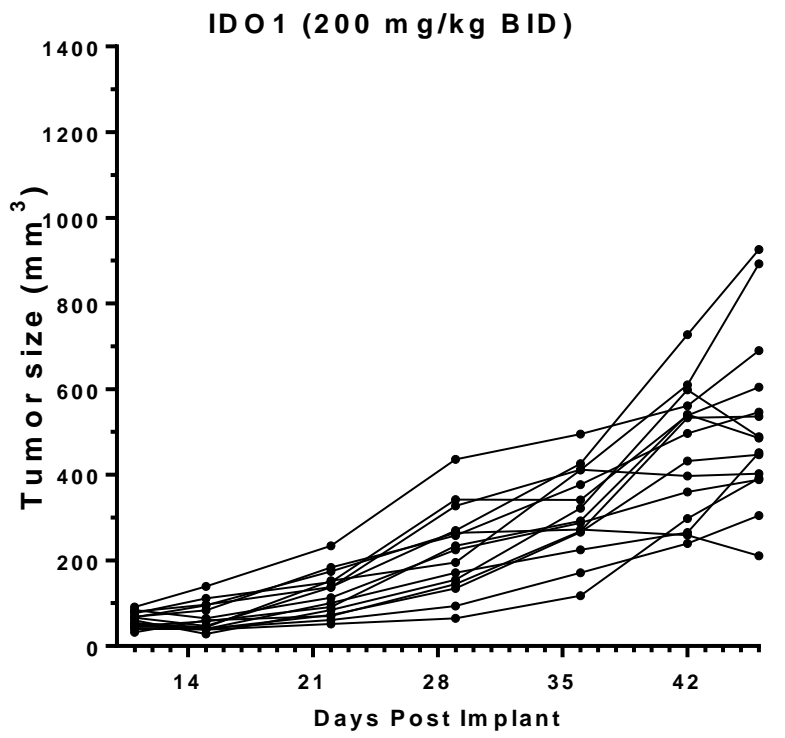

D $01(400 \mathrm{mg} / \mathrm{kg} \mathrm{BID})$

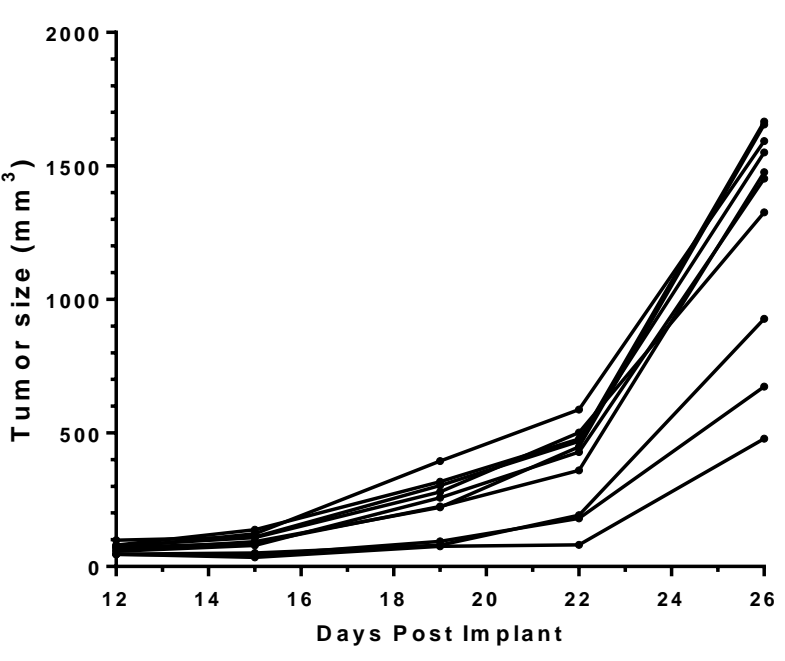

DO $1(200 \mathrm{mg} / \mathrm{kg} \mathrm{BID})$

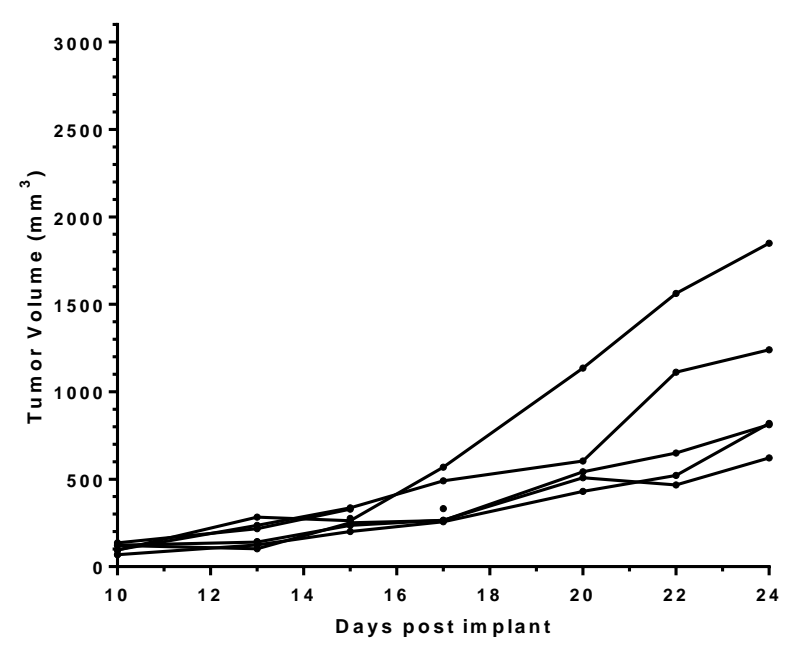

ID $01(600 \mathrm{mg} / \mathrm{kg} \mathrm{BID})$

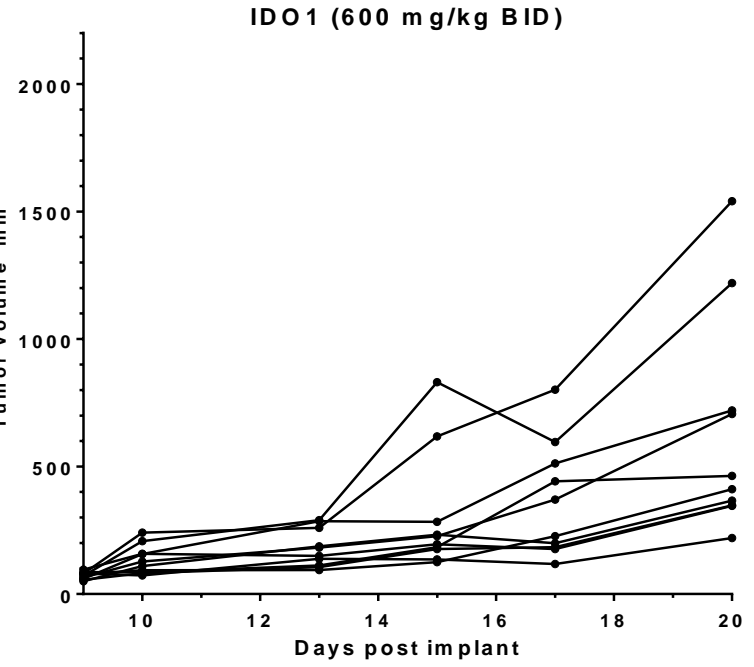

IDO1 $(200 \mathrm{mg} / \mathrm{kg} \mathrm{BID})$

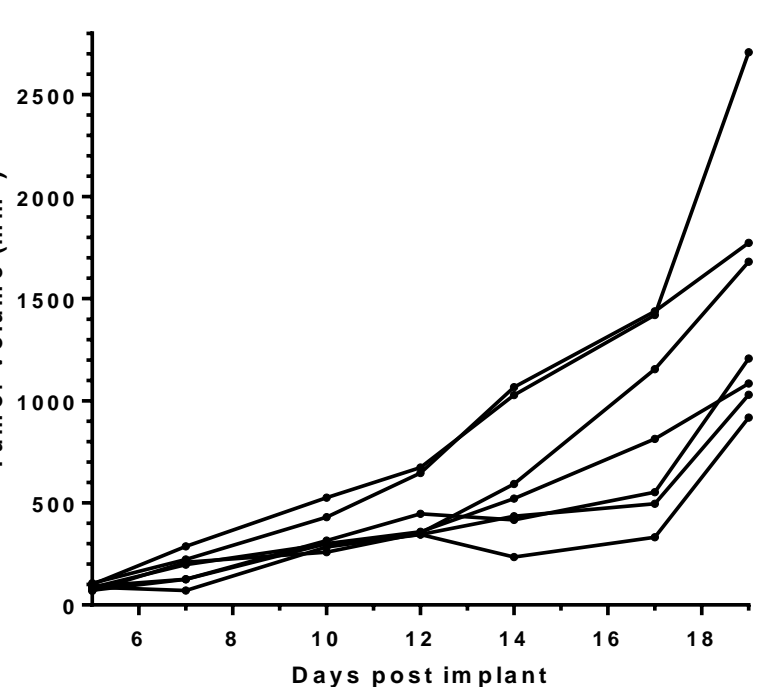

Figure 2 
A

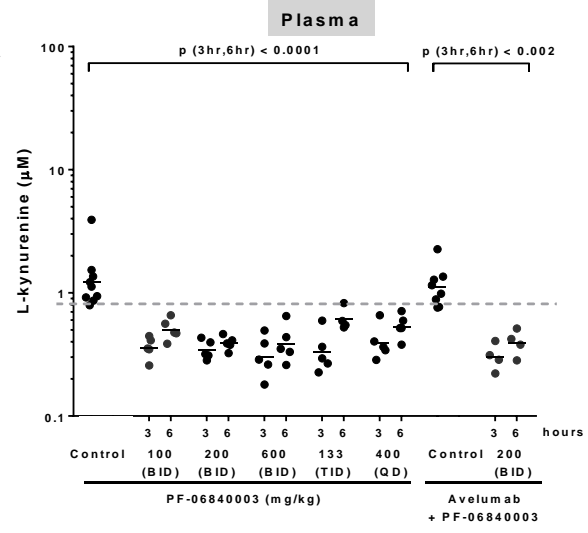

Tum or

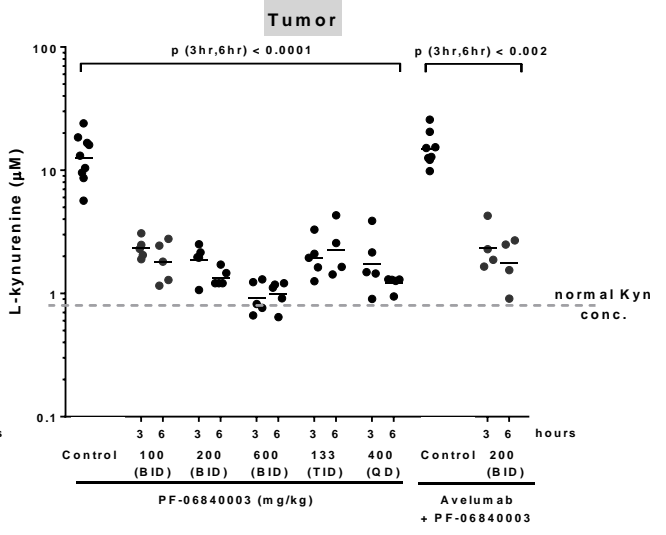

B

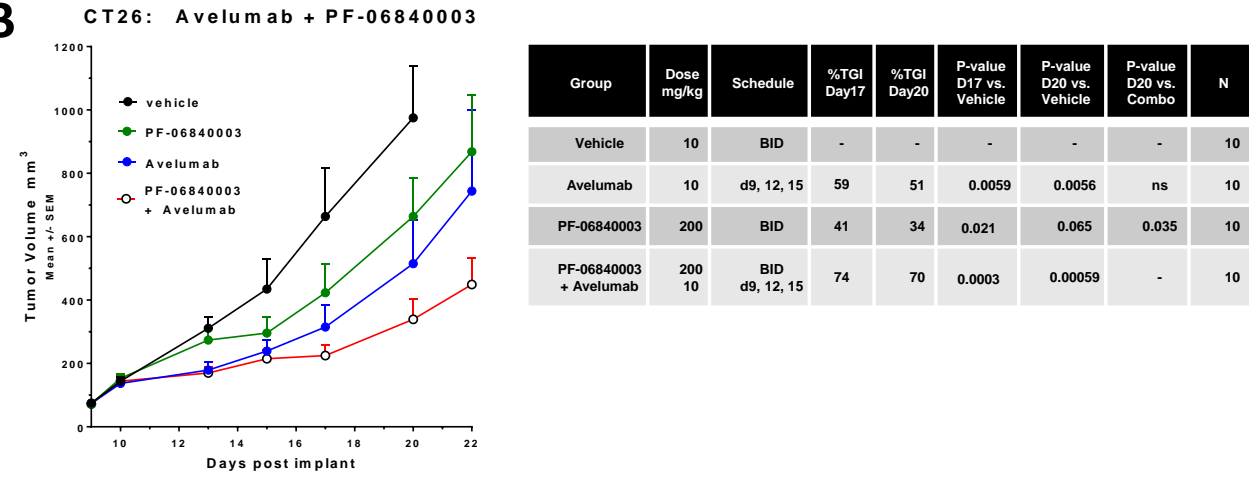

C

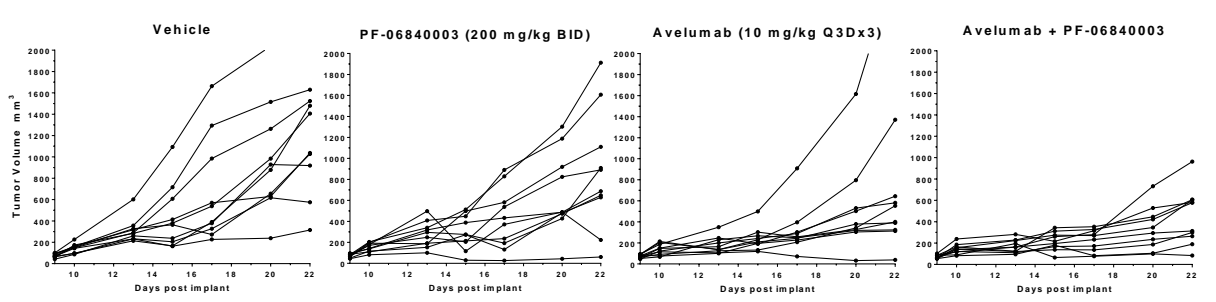

D

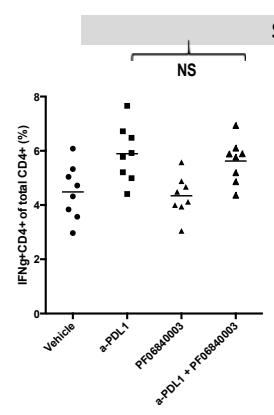

Spleen
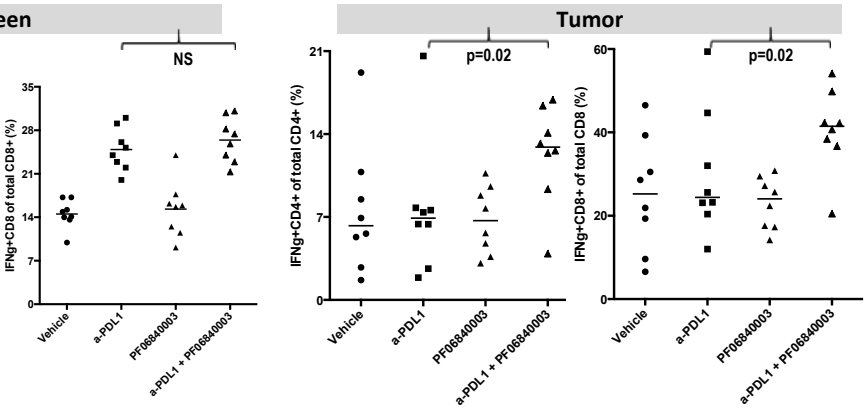

Figure 3. 
A

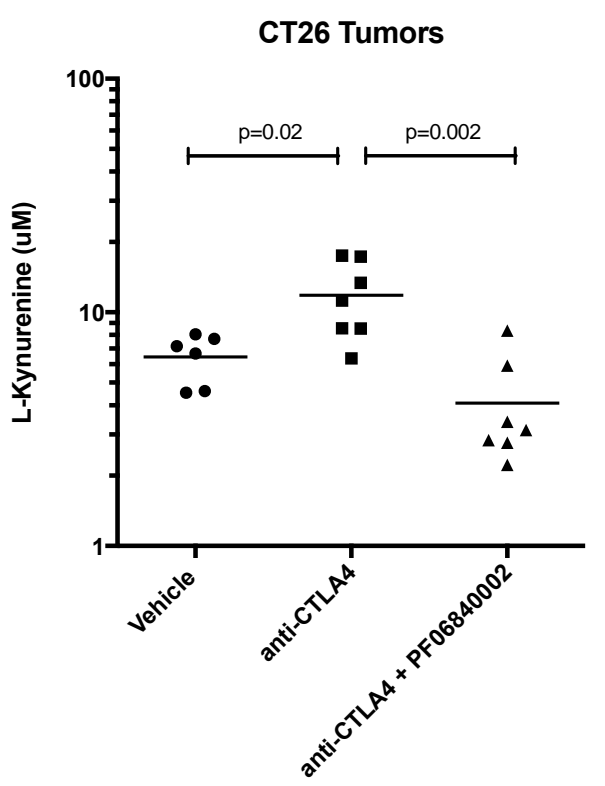

B

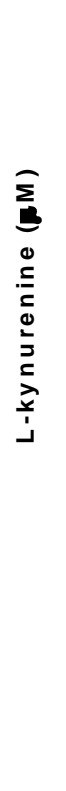

MC38 Tumors

Plasma

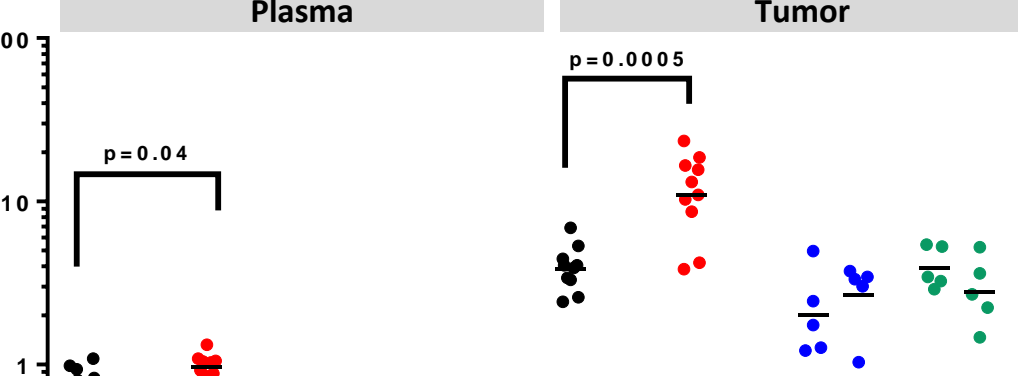

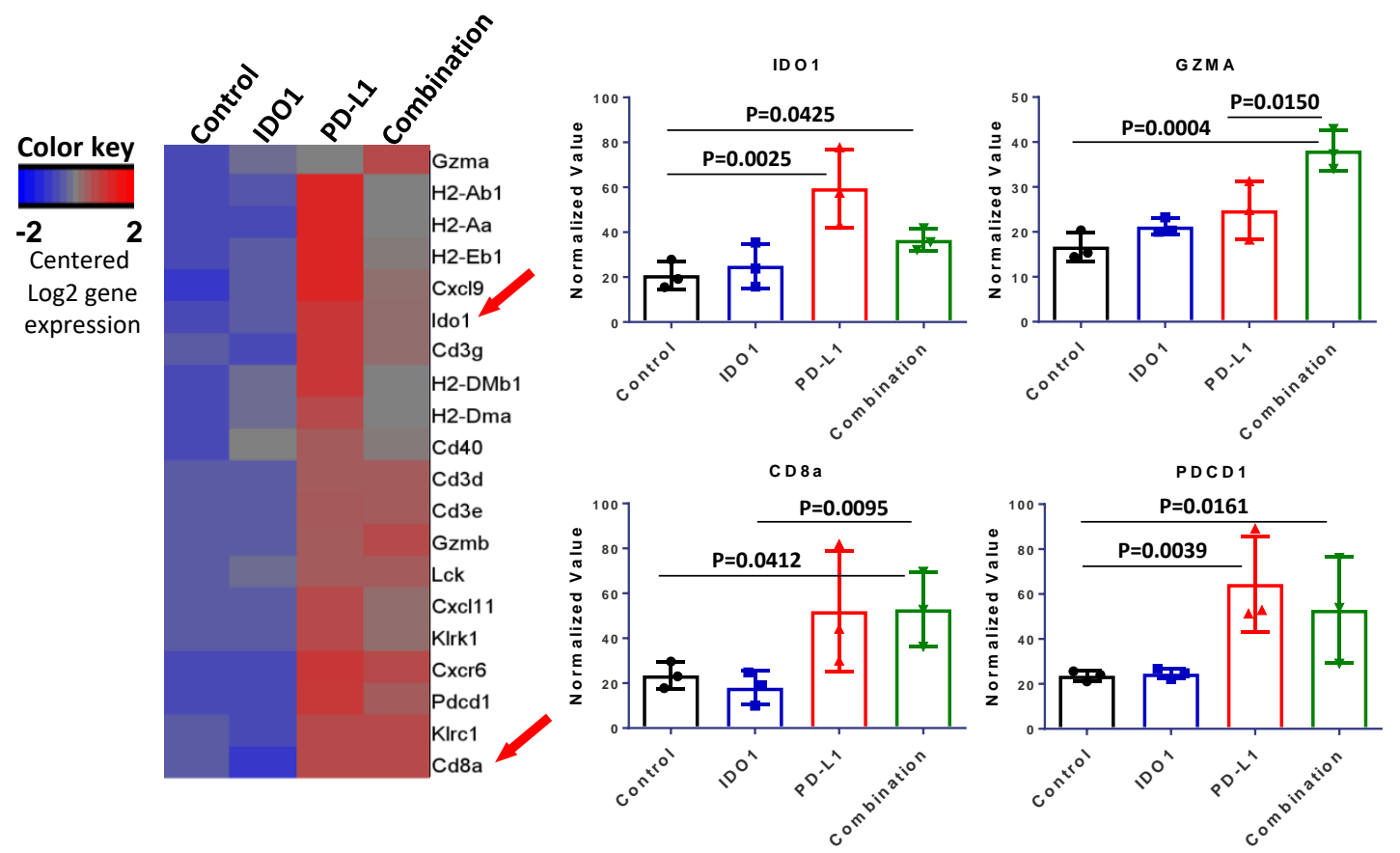

Figure 4. 